OPEN ACCESS

Edited by:

Alessandro Isidori,

AORMN Hospital, Italy

Reviewed by:

Jean El Cheikh,

American University of Beirut Medical

Center, Lebanon

Rohtesh S. Mehta,

University of Texas MD Anderson Cancer Center, United States

${ }^{*}$ Correspondence:

Justin Loke

j.loke@bham.ac.uk

Specialty section: This article was submitted to Hematologic Malignancies, a section of the journa

Frontiers in Oncology

Received: 09 February 2021 Accepted: 23 March 2021

Published: 15 April 2021

Citation:

Loke J, Vyas H and Craddock C (2021) Optimizing Transplant Approaches and Post-Transplant

Strategies for Patients With Acute Myeloid Leukemia.

Front. Oncol. 11:666091. doi: 10.3389/fonc.2021.666091

\section{Optimizing Transplant Approaches and Post-Transplant Strategies for Patients With Acute Myeloid Leukemia}

\author{
Justin Loke ${ }^{1,2^{*}}$, Hrushikesh Vyas ${ }^{1,2}$ and Charles Craddock ${ }^{1,2}$ \\ ${ }^{1}$ Centre for Clinical Haematology, Queen Elizabeth Hospital, Birmingham, United Kingdom, ${ }^{2}$ Cancer Research UK Clinical \\ Trials Unit, University of Birmingham, Birmingham, United Kingdom
}

Acute Myeloid Leukemia (AML) is the commonest indication for allogeneic stem cell transplantation (allo-SCT) worldwide. The increasingly important role of allo-SCT in the management of AML has been underpinned by two important advances. Firstly, improvements in disease risk stratification utilizing genetic and Measurable Residual Disease (MRD) technologies permit ever more accurate identification of allo-mandatory patients who are at high risk of relapse if treated by chemotherapy alone. Secondly, increased donor availability coupled with the advent of reduced intensity conditioning $(\mathrm{RIC})$ regimens has substantially expanded transplant access for patients with high risk AML In patients allografted for AML disease relapse continues to represent the commonest cause of transplant failure and the development of novel strategies with the potential to reduce disease recurrence represents a major unmet need.

Keywords: acute myeloid leukemia, allogeneic stem cell transplantation, graft-vs-host disease, graft-vs-leukemia, chemotherapy, MRD (measurable residual disease)

\section{INTRODUCTION}

Notwithstanding the advent of a number of novel chemotherapeutic agents for the treatment of Acute Myeloid Leukemia (AML) (1-3), allogeneic stem cell transplantation (allo-SCT) remains centrally important in the optimal management of fit adults with AML (4). Importantly, allo-SCT, consequent upon both dose intensification and the genesis of a potent donor-derived graft-vsleukemia $(\mathrm{GvL})$ effect still represents the most effective anti-leukemic therapy in adults with AML.

The last decade has seen a number of notable advances in the rationale use of allo-SCT in AML. Refinements in risk stratification of patients consequent upon the use of next-generation sequencing (NGS) (5), measurable residual disease (MRD) (6) and improvements in supportive care strategies (7) has led to more precise identification of patients who are likely to benefit from allo-SCT. At the same time the demonstration that reduced intensity conditioning regimens secure durable stem cell engraftment with a substantially lower toxicity has dramatically increased the upper age limit for allo-SCT and fit adults with AML up to the age of 75 can now be considered transplant candidates. Although a number of landmark studies of conditioning regimens have been performed in adult AML much remains to be done to personalize the transplant strategy according to both underlying disease biology and patient age and co-morbidities (8-11). At the same time the expansion of donor 
registries allowing increasing use of alternative donors as well as the advances in haploidentical transplantation have resulted in the great majority of allo-mandatory patients being able to access a donor $(12,13)$. Together these developments have cemented the position of AML as the leading indication for allo-SCT today (14).

Disease relapse however remains the commonest form of transplant failure in adults allografted for AML. Given the dismal outcome of patients with relapsed disease the development of pre-, peri- and post-transplant strategies with the potential to reduce the risk of disease relapse is now a priority and is essential if we are to improve transplant outcomes (15-17). Developments under investigation to reduce the risk of relapse post-transplant, include targeting pre-transplant MRD, optimizing the conditioning regimen and the use of maintenance therapy (18-21). At the same time the opportunity to combine either pharmacological or cellular interventions in the form of donor lymphocyte infusions (DLI) in patients with emergent disease remains an important alternative strategy to improve transplant outcomes.

\section{WHICH PATIENTS WITH AML SHOULD BE TRANSPLANTED IN FIRST REMISSION?}

Patients with AML who relapse often fail to achieve a second remission (22) and outcomes for patients allografted in CR2 as opposed to CR1 are unsatisfactory (23). Reasons for this include both differences in disease biology at relapse which reflects selection of chemo-resistant clones $(24,25)$ and reduction in patient fitness due to repeated treatment. It is therefore important, where possible, to ensure the identification of patients with AML likely to benefit from an allograft whilst they are in CR1. Deciding which patients with AML in CR1 should proceed to allograft is a dynamic process driven by a calculation of $i$ ) the relative risk of disease relapse if the patients receive intensive chemotherapy (IC) alone and ii) the predicted transplant related mortality (TRM) (Table 1). Over time, this decision process has evolved consequent upon both improved risk stratification for CR1 patients and significant reductions in TRM.
Pivotal studies by the HOVON group have demonstrated that the risk of relapse in patients allografted for AML in CR1 is more than halved in comparison with those who receive intensive chemotherapy alone and that this striking reduction is consistently observed in all cytogenetic subgroups (28-30). Allo-SCT should therefore be considered recommended in patients in whom the reduction in relapse risk delivered by an allograft offsets the attendant TRM of allo-SCT. According to the ELN guideline allo-SCT should be considered in fit adults with AML whose risk of relapse if treated with intensive chemotherapy alone is more than $40 \%$ providing a suitable donor is available $(5,31)$. In other words, for patients who are classified as "favorable risk" according to the 2017 ELN criteria, if their risk of AML relapse is less than $40 \%$, they should be treated with 3 to 4 courses of intensive chemotherapy and not be considered for an allograft. In contrast, allo-SCT has the potential to improve long term outcome in patients whose risk of relapse is higher than $40 \%$ (Table 1).

\section{Optimizing Risk Stratification for Patients With AML Treated With Intensive Chemotherapy Alone}

Risk stratification for patients with AML can be based on a combination of clinical, molecular and response assessment to treatment. The advent of NGS mutation subtyping and measurable residual disease (MRD) monitoring in adults with $\mathrm{AML}$ in CR1 have led to substantial advances in risk stratification.

\section{Clinical Variables Identifiable at Presentation}

Clinical factors predicting an inferior outcome in a patient with newly diagnosed AML include patient age, white cell count and the presence of secondary AML (32). Despite the availability of molecular and MRD assays to refine risk assessment these risk factors remain important in determining the risk of disease relapse (26) and who might benefit from an allo-SCT.

\section{Cytogenetic and Molecular Genetics Variables}

Karyotypic abnormalities are present in up to $60 \%$ of AML cases and permit classification of patients into populations with a

TABLE 1 | A table to demonstrate selection of patients for allogenic-SCT (Allo-SCT) with estimated relapse risk [Dohner et al. (5); Schuurhuis et al. (6)] with and without transplant and estimate of incidence of non-relapse mortality (NRM) following allo-SCT [Sorror et al. (26)].

\begin{tabular}{|c|c|c|c|c|c|}
\hline \multirow[t]{2}{*}{$\begin{array}{l}2017 \text { ELN risk } \\
\text { stratification }\end{array}$} & \multicolumn{3}{|c|}{ Estimated risk of relapse following consolidation with } & \multicolumn{2}{|c|}{$\begin{array}{c}\text { Maximal tolerated NRM } \\
\text { prognostic scores for allo-SCT to be considered }\end{array}$} \\
\hline & $\begin{array}{l}\text { MRD after cycle } \\
2 \text { chemotherapy }\end{array}$ & $\begin{array}{l}\text { Chemotherapy } \\
\text { alone (\%) }\end{array}$ & Allo- SCT (\%) & HCT-Cl score & NRM risk (\%) \\
\hline \multirow[t]{2}{*}{ Favorable } & Negative & 30 & $15-20$ & \multicolumn{2}{|c|}{ N/A (not advisable to proceed) } \\
\hline & Positive & 75 & $30-40$ & $3-4$ & $<30$ \\
\hline \multirow[t]{2}{*}{ Intermediate } & Negative & 55 & $25-30$ & 2 & $<20$ \\
\hline & Positive & 75 & 35 & $3-4$ & $<30$ \\
\hline Adverse & N/A & $>90$ & 50 & 5 & $<35$ \\
\hline
\end{tabular}

Adapted from Cornelissen and Blaise 2016 (27). 
favorable, intermediate and adverse overall survival if treated with intensive chemotherapy alone $(33,34)$. A large proportion of AML patients either fall into the intermediate risk group following cytogenetic analysis or have no cytogenetic aberration by conventional karyotyping. Molecular analysis has increasingly identified genetic mutations with biological and prognostic significance and importantly has transformed risk stratification for patients with no detectable cytogenetic abnormality.

In the last decade the presence of mutations in transcription factors, epigenetic modifiers, spliceosome and cohesin complexes have been integrated into the risk stratification of these patients through the widely adopted European leukaemiaNet (ELN) classification $(4,5,32,35)$. The ELN 2017 classification now utilizes both karyotypic abnormalities and the presence of mutations in NPM1, FLT3, CEBPA, RUNX1, ASXL1 and TP53 and this risk stratification has been validated in cohorts, primarily of younger patients with AML treated with intensive chemotherapy. The widespread adoption of NGS technology permits the routine identification of a range of additional prognostic mutations in AML and is likely to inform future risk stratification models. At the same time much work remains to be done in both determining the significance of such scoring systems in older adults treated with intensive chemotherapy and understanding the prognostic significance of distinct mutational signatures (36).

\section{Measurable Residual Disease}

In patients who have achieved a morphological CR quantitation of MRD provides an additional prognostic tool (Figure 1). Sensitive measurement of the MRD load can be achieved either using RQ-PCR, NGS methodology or multi-parametric flow cytometry (MFC) designed to detect MRD residual cells with a leukemia associated immunophenotype (LAIP) $(31,34)$.

With the variety of methods available to quantify MRD, the question arises as to which is the best modality to use and how useful the information obtained will be in patient management? The ELN has produced guidance on the integration of MRD status in the prognostication of patients and use in clinical trials (38). MFC methodologies have the advantage of being widely available and applicable to most cases of AML, but is less sensitive than RQPCR based technologies, at approximately 1 in 10000 (Figure 1) (39). The ELN suggest the use of $0.1 \%$ to distinguish between MFC MRD positive and negative status, derived from patient outcomes following induction chemotherapy, but values below this may still represent residual disease (40). There are differing analytic approaches in MFC MRD in AML. One method is to identify a leukemia-associated immunophenotype (LAIP) at diagnosis and track these changes through treatment, whereas another approach is to track leukemic cells by identifying aberrant differentiation and maturation profiles [Different from Normal (DFN)]. An approach adopted by many labs is to integrate the two techniques, but there is
A

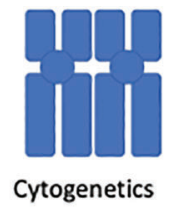

B

-

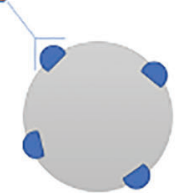

Flow cytometry

C

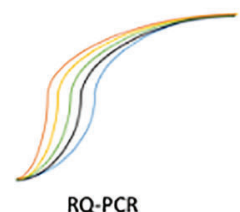

$R Q \cdot P C R$

Fing

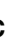

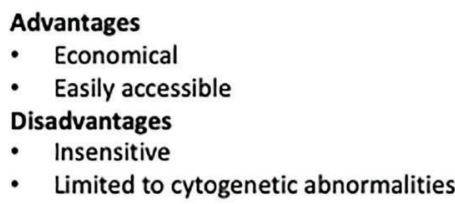

- Limited to cytogenetic abnormalities

Advantages

- Applicable to most AML cases

- Easily accessible.

Disadvantages

- Expertise required

- Low sensitivity if less than 8 colours used.

\author{
Advantages \\ - High sensitivity \\ Disadvantages \\ - May be limited to specific cytogenetic or genetic \\ abnormalities \\ - No possibility to find new variants
}

D

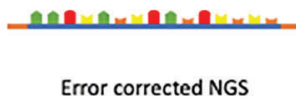

Error corrected NGS

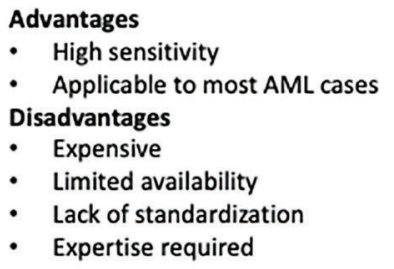

E

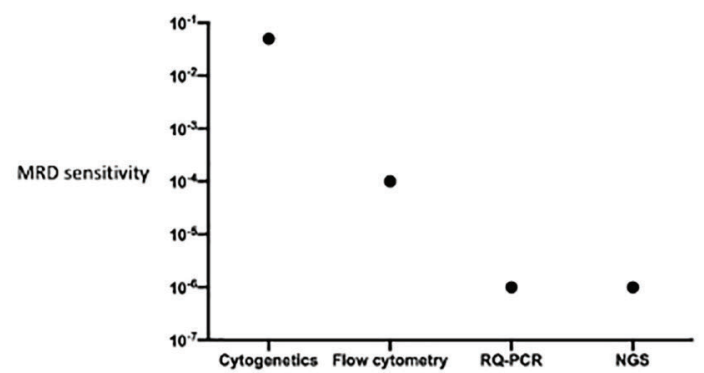

FIGURE 1 | A summary of the advantages and disadvantages of methods of MRD assessment, (A) cytogenetic analysis, (B) multi-parametric flow cytometry, (C) Quantitative polymerase chain reaction. (D) Next generation sequencing. (E) Represents the sensitivity of each method of MRD assessment method comparing the ability of each method to detect a single AML cell amongst normal haemopoietic cells. Sensitivities are as follows: Cytogenetics 1 in 20 , Flow cytometry 1 in 10,000, RQ-PCR 1 in 1,000,000, NGS 1 in 1,000,000. Data adapted from Ravandi et al. (37). 
disagreement as to the precise composition of the panels of antibody markers to identify different cell markers. As such, it is at present difficult to standardize MFC MRD between centers but attempts to develop unsupervised methodology may circumvent this limitation.

RQ-PCR based techniques have the ability to detect MRD at even lower thresholds, up to 1 in 1,000,000 cells. RQ-PCR assessment may be restricted to certain gene rearrangements and mutations; and is sometimes limited by novel breakpoints, especially in more infrequently occurring translocations. NGS is an exciting prospect allowing for the assessment of multiple gene loci and mutations in a single experimental run. However, the sensitivity of NGS is limited by its background error rate and a consensus on the methods available to correct some errors are still developing (41). In addition, consideration must be given to the targets analyzed by NGS, as although it provides the ability to look for a wide range of genetic variants in patient samples, the key is the ability to differentiate those mutations which have greater sensitivity for an impending relapse. For example, mutations found in clonal hematopoiesis of indeterminant potential (CHIP) may overlap with those in AML, but the relevance of their detection in the context of MRD is uncertain (42). Some of the limitations to the use of NGS in MRD are summarized in Figure 1. Error-corrected NGS MRD assays is at present prohibitively expensive in large cohorts of patients, and currently not available outside of an academic study, but has the potential to be widely adopted in the future due to the wide range of target mutations which can be monitored alongside the high sensitivity of the assay (43). Head-to-head comparisons of different MRD modalities, will be necessary to see which method will be of optimal use to patients, either individually or in combination. For example, a large study from the HOVON group demonstrated the additive prognostic benefit of MFC MRD with NGS based MRD methodology (42).

The use of MRD status may be integrated with ELN stratification to more accurately identify patients who may benefit from stem cell transplant. Importantly for patients who fall into the ELN 2017 favorable risk group, who would typically not be offered an allograft therapy, may have a predicted risk of relapse up to $70 \%$ on the basis of MRD results $(37,44,45)$. The benefit of allografting younger adults with NPM1+ AML who are $\mathrm{MRD}+$ after two courses of induction chemotherapy following induction chemotherapy patients has been confirmed in a recent ALFA Group study (46). RQ-PCR based MRD analysis of RUNX1-RUNX1T1 transcripts can also provide accurate discernment of relapse risk in otherwise favorable risk AML (47). Finally, RQ-PCR monitoring of AML transcripts can be used to detect molecular relapse which is a pre-cursor to hematological relapse (48). For example, in the case of mutated NPM1 AML, pre-emptive therapy can be delivered prior to an allogeneic stem cell transplant $(49,50)$. In younger patients with intermediate risk disease who lack a detectable molecular marker the presence of MFC MRD positivity assists with risk stratification and further supports a decision to proceed to allo-SCT in CR1 (51).

\section{Advances in Predicting Transplant Related Mortality}

It has long been known that patient fitness is an important determinant of transplant morbidity and mortality and yet assessing a patient's fitness pre-transplant remains a challengeparticularly in older patients with AML. A thorough clinical assessment at the "bedside" still remains of paramount importance but can now be complemented by a number of comorbidity scoring systems to inform decision making. The Hematopoietic Cell Transplantation Comorbidity Index (HCTCI) predicts TRM in patients undergoing an allo-SCT based on their comorbidities and has been validated in many large and independent cohorts (52) including a large cohort of patients with AML (53). It has more recently been adapted for mismatched donors (Augmented HCT-CI) (54). A HCT-CI score of 3 or more is associated with an increased risk of TRM and has been shown to provide better predictability when age is also taken into account (26). An alternative TRM assessment tool is the EBMT scoring system which was first devised to assess outcome of allogenic stem cell transplant for patients with chronic myeloid leukemia (55), but is now not widely used in assessing patients with AML (56). Whilst the EBMT scoring and HCT-CI take different parameters into account neither perform particularly well in older patients destined for RIC allografts where studies have shown an excess TRM in patients with an HCT-CI $>1$ (57). Attempts to combine the two methods to develop a compounded scoring system has been shown to improve TRM prediction $(55,56)$. Perhaps the most crucial limitation of any TRM scoring system is they do not account for the varying weight of a risk factor dependent on other transplant variables: for example, recipient CMV serostatus positivity are a particularly poor prognostic variable in 9/10 HLA matched donor allografts (58). Hence, the TRM estimate for any patients requires a personalized score based on patient, donor, disease and other transplant variables such as conditioning selection and GVHD prophylaxis strategy. The imprecision of any TRM prediction system is reflected by the fact that every transplant physician can recall a score of patients with a worryingly high HCT-CI- who sailed through their subsequent allograft.

Therefore, the aim of future models will be to combine such risk factors to provide a more personalized predictive scores to guide therapy, similar to what has been developed in myeloproliferative neoplasms (59). One way in which this may be possible is to improve the design of predictive algorithms through the use of artificial intelligence (60). These may allow for the advent of more complex algorithms with dynamic variables to account for the variable interaction between composite risk factors. For example, CMV seems to have a more profound negative impact on patients with low-risk disease than those with high-risk disease (56). However, the dynamic nature of these risks is illustrated by the use of Letermovir in CMV seropositive recipients (61), which may modify the impact of CMV infection on TRM to a hitherto undetermined extent. 
Identifying the Optimal Stem Cell Source

Identifying the optimal stem cell source is both a prerequisite to proceeding with an allo-SCT, and a major step in minimizing TRM. HLA matching at HLA-A, B, C and DRB1 (62) and in European centers at DQB1as well, resulting in an 8/8 or 10/10 HLA matched donor is the current standard of care in identifying either sibling or volunteer unrelated donors. Single HLA mismatches at these loci provide inferior outcomes, especially if recipients are CMV seropositive, with progressive decrements in outcomes with an increasing number of mismatches beyond $7 / 8$ or $9 / 10$ HLA matches $(63,64)$. With high resolution HLA typing, an HLA $10 / 10$ matched unrelated donor provided similar outcomes to those of an HLA matched sibling donor (65). Indeed, with the increasing age of patients with AML being considered for an allograft and by extension their sibling, a younger well matched unrelated donor may be preferable for reasons of donor health and data suggesting donor age may affect recipient overall survival, in the context of unrelated donors $(66,67)$. Similarly, in patients with multiple donors available, a number of rigorously performed studies suggests other factors may become important to consider $(58,62)$. Matching or permissive mismatching as predicted by $\mathrm{T}$ cell epitope prediction at HLA-DPB1 in recipient: donor (68) may lower the risk of non-relapse mortality. Increasing research into the impact of donor clonal hematopoiesis on recipients of an allo-SCT is likely to provide a further variable to consider for patients with more than one well matched stem cell donor (69).

Although the likelihood of identifying a HLA 10/10 matched unrelated donor for a Caucasian individual is over 75\% (12), a substantial number of patients with high risk AML may still lack a HLA $10 / 10$ or $9 / 10$ matched donor, notably those from ethnic minority backgrounds. For these individuals, a haploidentical or umbilical cord stem cell source is a donor source with acceptable outcomes (70-72). Given the results of transplantation with these alternative stem cell sources, it is unusual not to be able to identify a suitable donor for a patient with high-risk AML. Thereby, placing greater onus on the need to start donor searches at an early stage in patients' treatment pathway.

Whilst a number of retrospective studies have attempted to answer which alternative donor source is superior to the other a recent BMT CTN 1101 study was able to randomized patients to either an umbilical cord stem cell source or a haploidentical donor (73). The study closed prematurely due to slow recruitment, which may also affect the applicability of the results to contemporary practice. However, despite this, this important study has shown superior transplant related mortality in patients transplanted with a haploidentical donor as compared to those with an umbilical cord source, without a significant difference in relapse rates. This is in keeping with a large registry study which shows the superior outcomes in patients undergoing a RIC transplant with a haploidentical donor, in comparison with other alternative donors (74).

\section{TRANSPLANTATION OF PATIENTS WITH AML NOT IN CR1}

Patients with AML who do not achieve a remission after two cycles of induction chemotherapy are deemed to have primary refractory AML (38). The UK NCRI group recently studied more than 8,000 patients to compare the outcomes of patients with varying definitions of primary refractory disease (75). Regardless of the definitions of refractory disease, patients achieved long term survival rates in the region of $25-30 \%$ after allo-SCT. This is in concordance with other data that suggest long term survival following an allo-SCT is possible for patients with this aggressive sub-type of AML (76). Early identification of patients with primary refractory disease who may benefit from allo-SCT would improve the care of this patient group. For those considered fit for a myeloablative regimen, this is probably the optimal conditioning for their allo-SCT. In patients considered not fit for a myeloablative approach, the optimal conditioning regimen for patients with primary refractory AML has not been defined but optimism has been placed in adding (FLAMSA) sequential chemotherapy in a RIC regimen. For patients transplanted in CR2 and beyond, historical data confirms the role of allo-SCT (77) in providing a potentially curative pathway.

\section{APPROACHES TO REDUCE RISK OF RELAPSE POST STEM CELL TRANSPLANT}

Although there have been improvements in supportive care, the relapse rates for patients transplanted in CR1 remains unacceptably high at $30 \%-70 \%$ at 2 years $(8,10,78)$. Following relapse, prognosis for patients is generally poor, especially amongst patients who relapse early post-transplant. The 2-year survival for these patients remains in the region of $20 \%$ (79). The risk factors for relapse reflect disease biology and include the presence of FLT3-ITD (80), TP53 mutations (81), and high risk cytogenetic abnormalities (78). Disease status entering an alloSCT is one of the most important risk factors for relapse and overall survival, with historically poor outcomes identified in those entering transplant with active disease $(82,83)$. In more recent years, the assessment of pre-transplant MRD has shown outcomes in some studies where the risk of relapse posttransplant with pre-transplant MRD is high, and approaches that of those entering the transplant without a morphological remission (84). Relapse is higher in patients transplanted using a RIC regimen (85). Finally, the presence of MRD early posttransplant, regardless of methodology, is a potent risk factor for relapse $(86,87)$. Hence, approaches to reduce the risk of relapse can be roughly divided into pre-, peri- and post-transplant factors (Figure 2).

\section{Optimizing Pre-Transplant Factors What Is the Importance of Pre-Transplant MRD in Determining Transplant Outcome?}

A number of retrospective studies have demonstrated that MRD status pre-transplant is a strong predictor of disease relapse posttransplant although the effect size has been highly variable. Indeed, one study identified that the risk of relapse posttransplant in patients with AML in CR1 who have detectable pre-transplant MRD is comparable to that observed in patients 


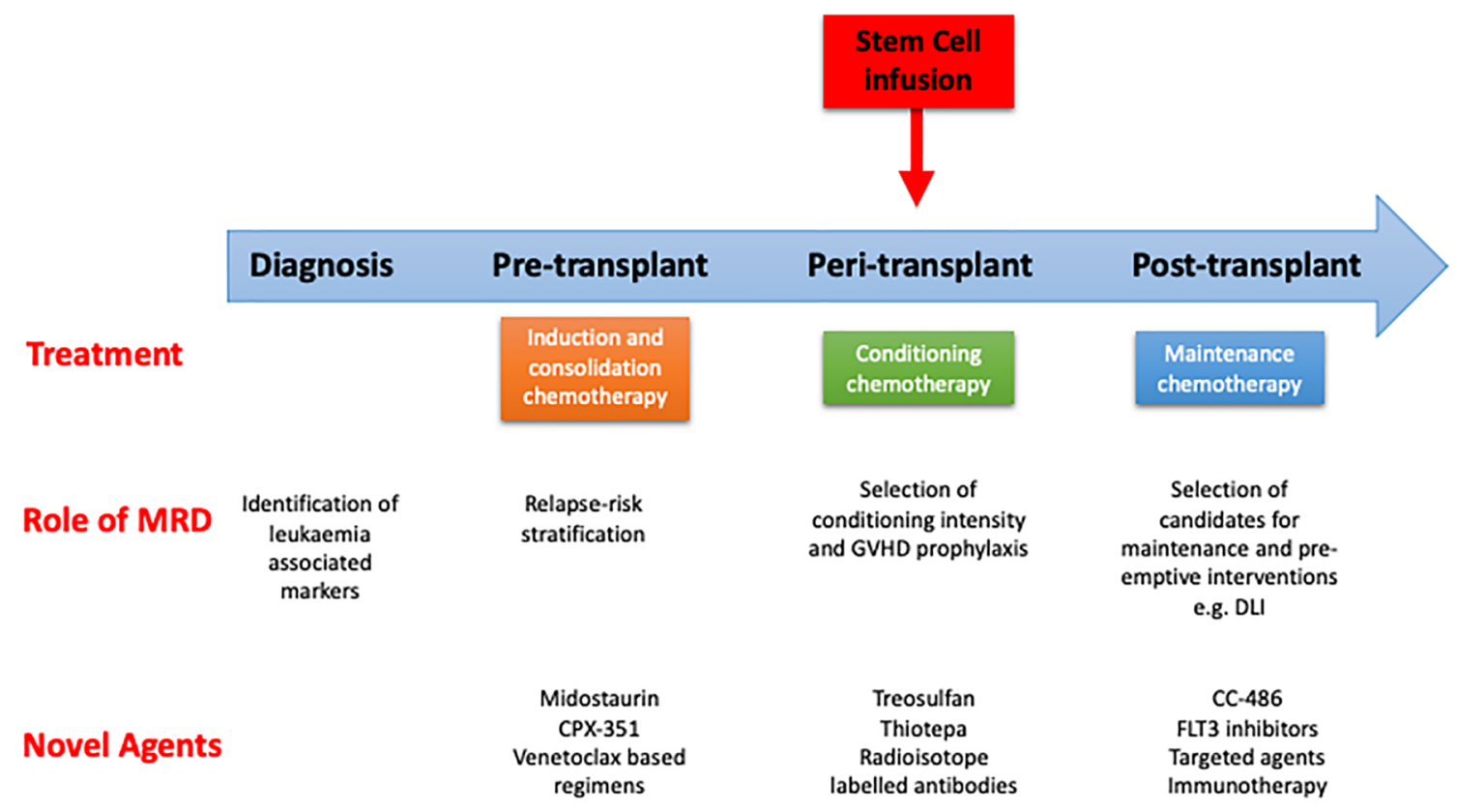

FIGURE 2 | Pathway of patient with AML undergoing curative treatment. Role of measurable residual disease (MRD) and novel agents at different stages. GVHD, graft vs host disease; DLI, donor lymphocyte infusion.

with active disease (84). A meta-analysis of 19 retrospective studies confirmed the predictive value of MRD status in terms of relapse risk and overall survival in patients allografted for AML (40) but until recently no prospective studies had addressed this critical question. The first prospective study demonstrated the predictive impact of pre-transplant MRD as measured by error corrected NGS in patients with AML (43). More recently the FIGARO study represented the first prospective evaluation of the prognostic impact of flow determined pre-transplant MRD in patients with AML and MDS. This study confirmed the increased risk of relapse in patients with pre-transplant MRD levels of $0.2 \%$ or above (11). Importantly, despite the increase risk of relapse in patients with higher levels of MRD, approximately $50 \%$ of patients survived at 2 years and therefore still stood to benefit from receiving a RIC allo-SCT, confirming the continued importance of allo-SCT in this sizeable patient population. Pre-transplant MRD measured by other modalities such as RTPCR or error corrected NGS has shown this has similar important prognostic value $(43,46)$. For example, in patients with NPM1 mutant AML, pre-transplant MRD positivity was associated with a poorer outcome post-transplant (49). Despite this, patients with a poor NPM1 MRD response to chemotherapy stood to benefit from allo-SCT as consolidation strategy (46). Given the prognostic significance of pre-transplant MRD there is now an urgent need to prospectively evaluate whether there is any benefit of interventions designed to reduce the MRD load pre-transplant (40) (Figure 2). A number of options exist including the use of novel formulations of standard chemotherapy, such as CPX-351, or agents such as venetoclax, both of which merit examination in a prospective randomized control trial.

\section{Can Pre-Transplant Therapy Be Optimized to Reduce Pre-Transplant MRD?}

There has been no prospective study that has examined whether treatment modification pre-allo-SCT has any impact in a) reducing pre-transplant MRD levels, or, b) increasing overall survival post allo-SCT. Firstly, there is no consensus on the optimum number of cycles of induction chemotherapy prior to allo-SCT. Retrospective studies looking at the impact of additional consolidation chemotherapy with cytarabine following remission induction in patients undergoing reduced intensity or myeloablative conditioning failed to show any significant benefit in terms of overall survival or disease relapse $(39,88)$. Prospective studies in this area are lacking and so we do not know whether there is any benefit or harm from additional chemotherapy cycles following induction. However, data from patients with primary refractory AML suggest that additional courses of chemotherapy in patients with chemo-resistant disease is detrimental (75).

In recent years, a number of novel agents as part of induction and consolidation strategies have received FDA approval (2, 89, 90 ), and provide some provocative, preliminary, data to suggest that optimizing pre-transplant chemotherapy has an impact on post-transplant outcomes. The use of midostaurin as an adjunct to conventional chemotherapy in induction, consolidation and maintenance phase has demonstrated overall survival benefit in a randomized controlled trial (2) in patients with FLT3 mutant 
AML. From these patients, approximately 55-60\% underwent allo-SCT and in this subset of patients a trend to benefit was retained in those receiving midostaurin as compared to control (2). Novel FLT3 inhibitors such as Gilteritinib and Quizartinib provide a route for patients with relapsed FLT3 mutant AML to achieve remission and to further consolidation with an allo-SCT $(91,92)$.

Similarly, in a trial comparing CPX-351 to conventional DA $3+$ 7 , benefit in terms of overall survival and remission rates in patients in the CPX-351 arm was seen but interestingly this significant survival benefit was retained when comparing patients in the CPX351 arm compared to standard therapy in patients who subsequently underwent an allo-SCT (93). As there could be potentially a number of mechanisms behind the survival advantage of these novel agents in the cohort of patients who have received an allo-SCT, it will be important in future studies to incorporate pre-transplant MRD to ascertain if this advantage is a result of a deeper remission status. Hence, there is a need for further adequately powered, randomized, prospective trials to assess if these agents improve pre-transplant MRD and reduce risk of relapse post-allo-SCT. It is of particular interest that an ongoing randomized control trial investigating the benefits of CPX-351 vs intermediate dose cytarabine at consolidation, will assess the impact of this cycle of treatment on MRD pre-transplant, and subsequent post-transplant outcome (COSI, NCT04217278).

The improvements in remission rates and survival in patients receiving venetoclax in addition to azacitidine (94) has increased the number of patients being considered for an RIC allo-SCT who otherwise may not have attained a remission to reach this treatment stage. It remains to be seen whether the depth and quality of remissions achieved in patients with venetoclax based combinations are comparable to patients receiving conventional intensive chemotherapy prior to an allo-SCT, and whether, this has any long-term significance in their overall survival. The use of venetoclax based regimens may enable patients to reach an allo-SCT with a reduction in morbidity. This is similar to the use of azacitidine to achieve remission, prior to allo-SCT, in elderly patients (95).

\section{Optimizing Peri-Transplant Factors for Patients With AML Historical Development of Conditioning Regimens for Patients With AML}

The role of the conditioning regimen in allo-SCT in patients with AML is to allow durable engraftment of the donor stem cells and to deliver a direct cytotoxic anti-leukemic effect. This was illustrated by early observations, in patients with AML, that conditioning intensity correlated with relapse risk (96). Myeloablative regimens (MAC) arose from the origins of hematopoietic stem cell transplantation (97) and such regimens are defined by the induction of permanent bone marrow aplasia, in the absence of hematopoietic stem cells infusion. Important studies to support the benefits of allo-SCT in patients undergoing myeloablative sibling allografts for AML in CR1 compared the outcomes of patients with AML who had an HLA-matched sibling donor for allo-SCT, or not (28) ("donor vs no-donor" methodology). The benefits of such intensive regimens were only seen in patients under 40 years of age, due to an excess in TRM (28) in the patients older than 40 years of age.

MAC regimens historically combined Cyclophosphamide (Cy) with either TBI or busulfan $(\mathrm{Bu})$ and remain in common use. However, new developments in conditioning regimens have extended the applicability of MAC regimens. Critically, intravenous preparations of busulfan have led to more predictable pharmacokinetic properties and better tolerability such that they are at least equitable to TBI based regimens. Indeed, one prospective study suggested a superior overall survival in patients treated with a $\mathrm{Bu}$ - as opposed to a TBI- based regimen (98). This randomized control trial (RCT) demonstrated a marked improvement in NRM for Fludarabine (Flu)/Bu4 (12.8 mg/kg over 4 days of IV busulfan) over an iv-Bu/Cy regimen (same dose of busulfan), in a population of patients aged 40-65. As such Flu/Bu4 is now widely used as a standard of care regimen for patients receiving an allo-SCT as a MAC protocol.

Reduced intensity conditioned (RIC) regimens have played an important role in extending the age at which adults with high risk AML can be safely allografted. A RIC regimen is defined as incorporating $\leq 8$ Gy Total Body Irradiation (TBI) or $\leq 8 \mathrm{mg} / \mathrm{kg}$ busulfan (99) and a number of variously myelosuppresive and immunosuppressive iterations exist. Taken together however the advent of RIC regimens has dramatically extended the spectrum of patients with AML who may be a candidate for a RIC alloSCT, such that fit patients with AML in remission over the age of 75 are now routinely transplanted in many transplant centers with acceptable results $(100,101)$. The optimal RIC regimen has not yet been established and is likely to depend on both underlying disease biology, patient age and donor source. One of the first randomized studies in AML compared outcomes in patients allografted with a Flu/Bu2 $(6.4 \mathrm{mg} / \mathrm{kg}$, two days of IV busulfan) RIC regimen and a non-myeloablative Flu/2Gy TBI regimen, Despite a similar overall survival in both groups, there were significant differences in TRM and relapse rates with a markedly higher relapse rate in the Flu/2GyTBI regimen (102). A more recent study compared the $\mathrm{Flu} / \mathrm{Bu} 2$ regimen with a $\mathrm{Flu} /$ Treosulfan ( $10 \mathrm{~g} / \mathrm{m}^{2}$ for 3 days) regimen This demonstrated noninferiority between the two regimens, with similar relapse rates, but a reduction in TRM for patients treated on Flu/Treosulfan arm (103), although interpretation of this study is hampered by the unusually high TRM seen in the Flu/Bu2 arm of the study. In an attempt to reduce relapse rates post-transplant, which remains the major cause of treatment failure after a RIC alloSCT, the addition of sequential chemotherapy to transplant conditioning has been compared to standard RIC regimens. The FIGARO study demonstrated that the FLAMSA-Bu regimen did not improved survival or relapse risk as compared to a standard RIC regimen in patients with high risk AML or MDS (11).

\section{Should the Presence of Pre-Transplant MRD in Patients With AML in CR1 Influence the Intensity of the Conditioning Regimen?}

A number of randomized trials have sought to determine whether a RIC or MAC regimen is preferable in patients with AML in CR1 
aged between 40-60 with AML or MDS. To date three studies have directly addressed this important question (9, 10, 104, 105). However, as a result of the enduring challenge of achieving timely recruitment to randomized transplant trials two were underpowered which complicates their interpretation. Of note two studies have demonstrated similar outcome with either AML or MDS transplanted using a MAC or RIC regimen $(104,105)$. In contrast a more recent US BMT CTN (0901) study which recruited briskly and randomized patients to either a RIC or MAC regimen showed a higher rates of relapse in patients transplanted using a RIC regimen. Although this resulted in an inferior RFS there was no statistically significant difference in survival between the two arms (9) in the original report. A recent update with long term follow up, suggest that there is a superior OS in the MAC as compared to the RIC arms of the study (106). Interpretation of this important trial is however complicated by the unexplained discrepancies between the relapse rates observed in both RIC AND MAC arms compared with those observed in other studies.

An important further consideration is whether the choice of conditioning regimen should be determined by pre-transplant MRD status. In important adjunctive studies of the BMT CTN 0901 cohort Hourigan demonstrated improved survival in MRD+ patients with AML who were transplanted using a MAC as opposed to a RIC regimen. Of interest the outcomes of MRD- patients who received either a MAC or RIC was equivalent. In contrast no clinical benefit was observed in $\mathrm{MRD}+$ patients transplanted using the intensified sequential FLAMSA regimen in the FIGARO trial (11).

Further studies are therefore required in order to robustly examine the optimal conditioning regimen in patients with detectable MRD pre-transplant (43). Due to the likely beneficial impact of myeloablative conditioning on relapse risk, patients should be assessed on an individual basis to determine the likely benefits of a more intensive conditioning regimen. A RIC regimen is to be preferred in older patients in whom the TRM of a MAC regimen is deemed likely to be excessive. In the sizeable population of older patients who will, force majeur, be transplanted using a RIC regimen post-transplant strategies aimed at maximizing a GVL effect should be prioritized.

\section{Can We Increase the Anti-Leukemic Properties of Conditioning Regimens Without Excess Toxicity?}

Thiotepa is an alkylating agent that has been used in a number of transplant conditioning regimens, including a Flu/Bu/Thiotepa regimen which had been used for patients undergoing umbilical cord transplants with low relapse risks (107). In recent years promising results have been seen when thiotepa $(5 \mathrm{mg} / \mathrm{kg} /$ day for 2 days) has been added to $\mathrm{Flu} / \mathrm{Bu}$ regimens (fludarabine $50 \mathrm{mg} /$ $\mathrm{m}^{2} /$ day for 3 days, busulfan at $3.2 \mathrm{mg} / \mathrm{kg} /$ day for 3 days) (108) in reducing relapse risk in patients with AML in CR1 $(109,110)$. The COSI study is a randomized control trial currently undergoing recruitment and will compare the Flu/Bu4 regimen with the Flu/Bu/Thiotepa schedule in patients under 55 years of age, whilst those over 55 years will either receive a $\mathrm{Flu} / \mathrm{Bu} 2$ schedule or a miniThiotepa/Bu/Flu regimen (thiotepa $5 \mathrm{mg} / \mathrm{kg}$ for 1 day, fludarabine $50 \mathrm{mg} / \mathrm{m}^{2} /$ day for 3 days, busulfan $3.2 \mathrm{mg} /$ $\mathrm{kg} /$ day for 2 days).
Conditioning chemotherapy may also be sequenced in novel regimens to allow older patients to have more potent treatment (111). Another strategy that remains in development is the use of radio nucleotide labelled antibodies to reduce the side effects experienced with conventional chemotherapy-based conditioning regimens. One example that is undergoing clinical trial is the 131iodine labelled anti-CD45 antibody (112). BC8, delivered as part of conditioning alongside fludarabine and 2 Gy TBI. CD45 is a promising target due to its widespread expression on hematopoietic cells but not in non-hematopoietic tissue, thereby potentially reducing the incidence of adverse effects.

\section{Optimizing GVHD Prophylaxis}

Both acute and chronic GVHD are an important cause of morbidity and mortality. Hence a composite outcome measure for studies in allo-SCT has been rapidly established which combines GVHD and relapse free survival (GRFS) (113). An early observation in the history of allogeneic stem cell transplantation was that GVHD was inversely correlated with the risk of relapse, supporting the presence of a graft-vs-leukemia effect (114). This has been reinforced by later observations that the level of cyclosporine exposure through dosing, especially in the early days of transplant can significantly influence the risk of relapse $(115,116)$. T cell depletion (TCD) can be used to reduce the incidence of GVHD (117) and in vivo strategies involving anti-thymocyte globulin (ATG) or anti-CD52 antibody (alemtuzumab) are in routine use $(118,119)$. However, TCD as compared to T replete transplants, are associated with increased risk of disease relapse (120), viral infections (e.g. CMV) (121), and a significant incidence of mixed donor: recipient chimerism in the $\mathrm{T}$ cell fraction. Further developments in GVHD prophylaxis continues with increasing uptake of post-transplant cyclophosphamide, beyond the setting of haploidentical donor transplants, into patients receiving a MUD allo-SCT $(122,123)$, although a definitive prospective study comparing these different forms of GVHD prophylaxis remains to be seen, but are underway (124). In the future, optimizing GVHD prophylaxis may involve taking into account different factors including disease risk, donor source, and conditioning regimen.

\section{Optimizing Post-Transplant Strategies for Patients With AML}

The risk of relapse in patients allografted for AML ranges between $30-70 \%$ and is dependent on disease biology, remission and MRD status pre-transplant and conditioning regimen intensity $(29,125)$ (Figure 2). These risk factors identify a cohort of patients with a high risk of relapse post allo-SCT in whom post-transplant strategies to reduce this risk is urgently required. A further complication in the management of this post-transplant period is the variability in post-transplant recovery and potential other complications such as infection and GVHD which will influence the feasibility of any pharmacological intervention. Therefore, post-transplant strategies to prevent relapse, as in other aspects of transplant care, should be optimized to the individual.

\section{Post-Transplant Strategies to Monitor Disease}

The presence of detectable MRD at early time-points posttransplant is associated with a very high risk of relapse (126) 
and this has been confirmed using NGS MRD technologies (86, 127). For example in $t(8 ; 21)$ AML, failure to achieve a $3 \mathrm{log}$ reduction in transcripts, as compared to baseline pre-treatment levels, by month 3 post-transplant is associated with a $51 \%$ risk of relapse as compared to only $8 \%$ in those who achieve this landmark (128). As a consequence, there is increasing interest in routine monitoring of MRD post-transplant in patients allografted for AML. However, the complexity in interpreting post-transplant MRD results is exemplified in the context of NPM1 monitoring where post-transplant relapse risk is dependent on the level of MRD (129). Of note, not all patients with detectable MRD post-transplant proceed to overt relapse suggesting the possible role of an emergent GvL effect in disease control. However, the detection of MRD post-transplant mandates urgent consideration of interventions such as a use of donor lymphocyte infusions (DLI). Such interventions are more effective in patients with a lower disease burden $(130,131)$ and hence maybe more effective in molecular relapse, prior to hematological relapse $(132,133)$. Likewise, the experience of using azacitidine post allo-SCT with relapsed AML, blast percentage in the marrow is an independent prognostic factor for survival (16).

Donor: recipient chimerism monitoring can be accomplished routinely either by short tandem repeat (STR) or sex difference between donor and recipient using PCR. This test can be done on whole blood or specific subsets such as myeloid, T Cell or CD34+ cells (134). Although, the sensitivity of this is limited to $0.1-1 \%$ depending on methodology, falling donor chimerism is associated with an increased risk of relapse (135). The challenge in using mixed chimerism levels as a risk factor for disease relapse, is that in RIC allografts, incidences of mixed chimerism is commonly seen and is related to pharmacological levels of $\mathrm{T}$ cell depleting agents such as alemtuzumab (136). Chimerism can also be altered by other factors including viral reactivation, changes in immunosuppression, affecting interpretation of results (137). Fundamentally this is a result of the fact that chimerism is not a direct marker of disease.

The recent report of the FIGARO study has demonstrated the importance of interpreting pre-transplant MRD with posttransplant chimerism monitoring (11). This study demonstrated that the acquisition of full donor chimerism at 3 months mitigated the increase risk of relapse from positive pre-transplant MRD. This may provide the rationale for interventions that can increase the kinetics of attaining full donor chimerism such as modifications in immunosuppression strategies.

\section{New Developments in Post-Transplant Maintenance Strategies}

Post-transplant pharmacological interventions may deliver produce a direct cytotoxic effect, and augment the effects of the conditioning regimen, enabling sufficient time for the development of an allo-reactive $\mathrm{T}$ and $\mathrm{B}$ cell response against leukemic cells. However, it is also increasingly recognized that pharmacological agents may interact with the immune system to accelerate the development of a graft-vs-leukemia effect, as seen in the metabolic re-programming of leukemia reactive T-Cells in patients treated with sorafenib post-transplant (138). Development of maintenance strategies post allo-SCT are dependent on the use of agents with a) clinical activity, b) tolerable side effect profile, and which does not exacerbate cytopenias, infection rates and graft-vs-host disease. Finally, it is unclear whether maintenance strategies definitively prevent relapse or merely delays it which relates to uncertainty over the duration with which these agents should be used. Nevertheless, such strategies, even it were to delay relapse may allow the development of an effective graft vs leukemia effect through immune reconstitution.

\section{Non-Targeted Agents}

The use of non-mutation specific agents has the advantage that it is not susceptible to changes in clonal landscape that occurs preand post- transplant relapse $(139,140)$. Lenalidomide is effective at relapse of AML (17) in combination with azacitidine, however this may exacerbate GVHD if used as maintenance therapy alone (141). Azacitidine has been shown to be well tolerated posttransplant and may both reduce risk of GVHD through expansion of regulatory $\mathrm{T}$ cells and increase GvL effect by upregulating the expression of cancer testes antigens on leukemia cells (18) which is associated with a reduced risk of relapse (19). In a randomized control study, the subcutaneous administration of azacitidine, as compared to control, did not provide any additional benefits to patients with AML post alloSCT, but this study was notable for a short on-treatment duration (142). In the RELAZA2 study, MRD measurement through donor chimerism measurement in CD34+ selected cells in post allo-SCT patients was used to select patients who would receive pre-emptive azacitidine (21). This strategy lengthened the duration of relapse free survival, in comparison to their historical experience. Much interest has been shown in the oral azacitidine formulation (CC-486), given its results in improving overall survival in elderly patients with AML who are ineligible for allo-SCT (143). In the post allo-SCT setting, CC486 can be given with acceptable side effects (144) resulting in an ongoing phase III randomized control trial (NCT04173533). The HDAC inhibitor, Panobinostat has also been used as part of a maintenance strategy post allo-SCT in MDS or AML as part of a phase I/II study and has shown encouraging rates of GVHD as well as improved relapse and survival, leading to a phase III trial in this setting (NCT04326764).

\section{Targeted Agents}

A number of targeted agents designed against specific key pathways in AML has shown anti-leukemic activity in newly diagnosed and relapsed-refractory patients, resulting in a number receiving Food and Drug Administration (FDA) approval (145). Importantly many of these new agents are tolerable and can be administered in the outpatient setting, which is vital for any maintenance strategy. The hedgehog signaling pathway is important in embryonic development, and aberrant activity in this pathway is associated with chemoresistance in pre-clinical models of AML (146). Glasdegib, is an inhibitor of the hedgehog pathway and when used with low 
dose cytarabine (LDAC) was superior to LDAC alone, with a short improvement in overall survival in a randomized phase II study (147). With these results the use of glasdegib as maintenance post allo-SCT in patients with high risk AML is undergoing a phase II clinical trial. IDH1 and 2 inhibitors, given its anti-leukemic activity and tolerability $(148,149)$ maybe a useful maintenance option for patients with IDH1/2 mutant AML.

FLT3 is a member of the type 3 receptor tyrosine kinase family (150), mutations of which can be found in approximately $30 \%$ of patients, and is associated with increased relapse rates (151). Despite an allo-SCT, patients with FLT3-ITD mutant AML have an increased relapse rate as compared to patients with FLT3-ITD negative AML (80). Recent years have seen the clinical development of a number of FLT3 inhibitors both in frontline (2) and in the relapse-refractory setting (91, 92). First generation FLT3 inhibitors such as sorafenib, lestaurinib and midostaurin have a wider spectrum of activity against other receptor tyrosine kinases, with a broader adverse event profile and less potent monotherapy activity. However, despite this, in combination with induction chemotherapy, sorafenib improved relapse free survival (152), and in the case of midostaurin, improved overall survival. Interestingly, in the case of sorafenib, improvements in relapse free survival were irrespective of FLT3 mutation status. The RATIFY study, which allowed midostaurin to receive FDA approval was not designed to examine the role of midostaurin as post allo-SCT maintenance. Midostaurin has been used as a post allo-SCT maintenance agent in two studies. In a study of 284 patients with FLT3-ITD AML, midostaurin was used in combination with induction chemotherapy followed by allo-SCT for 12 months of maintenance (153). The results of this study were not definitive, as the outcomes could only be compared with historical controls. Similarly, a small phase II randomized control study compared midostaurin to placebo as a maintenance post allo-SCT, which showed that this agent was tolerable but the study was insufficiently powered to show statistical significance (154). Much enthusiasm for the use of sorafenib post allo-SCT was generated by the SORMAIN study (20) which although required five years for completion, and was stopped due to incomplete recruitment, demonstrated improved overall survival and reduction in relapses, albeit in small numbers. However, another randomized controlled study of Sorafenib vs control has also shown similar results to the SORMAIN study (155). Although some centers now routinely use this agent as post allo-

\section{REFERENCES}

1. Castaigne S, Pautas C, Terre C, Raffoux E, Bordessoule D, Bastie JN, et al. Effect of gemtuzumab ozogamicin on survival of adult patients with de-novo acute myeloid leukaemia (ALFA-0701): a randomised, open-label, phase 3 study. Lancet (2012) 379(9825):1508-16. doi: 10.1016/S0140-6736(12) 60485-1

2. Stone RM, Mandrekar SJ, Sanford BL, Laumann K, Geyer S, Bloomfield CD, et al. Midostaurin plus Chemotherapy for Acute Myeloid Leukemia with a FLT3 Mutation. New Engl J Med (2017) 377(5):454-64. doi:10.1056/NEJMoa1614359
SCT maintenance for FLT3-ITD AML, the tolerability of this agent remains debatable and questions remain over the validity of these results in the era of patients routinely receiving midostaurin at induction pre allo-SCT (156). It is in this context that second generation FLT3 inhibitors which are more specific and have potency as monotherapy, even in relapsed refractory AML such as Quizartinib and Gilteritinib $(91,92)$ may be important as maintenance post allo-SCT, and the results of the BMT-CTN 1506 study which compares Gilteritinib to control post allo-SCT and has completed accrual, is eagerly awaited.

\section{Summary}

Allo-SCT now plays a central role in the management of adult AML. Yet much remains to be done improving transplant outcomes. Randomized clinical trials of novel strategies to reduce the risk of disease relapse post-transplant are now a priority. Allo-SCT provides an important platform to manipulate the immune environment against residual leukemic cells. For example, use of check-point inhibitors and other cellular therapies may become important in the future (157-159). At the same time, it is increasingly clear that integrated MRD and genomic analyses will increasingly permit adoption of personalized transplants. The effective delivery of such studies will demand a greater spirit of collaboration between clinicians and basic scientists as well as the establishment of effective national and international transplant trials networks.

\section{AUTHOR CONTRIBUTIONS}

All authors contributed to the writing of this review article. All authors contributed to the article and approved the submitted version.

\section{FUNDING}

Research support and clinical trials funding from CRUK, Bloodwise and Cure Leukaemia acknowledged. Core funding to the Birmingham ECMC Centre program is gratefully acknowledged. The funder bodies were not involved in the study design, collection, analysis, interpretation of data, the writing of this article or the decision to submit it for publication.

3. Wei AH, Montesinos P, Ivanov V, DiNardo CD, Novak J, Laribi K, et al. Venetoclax plus LDAC for newly diagnosed AML ineligible for intensive chemotherapy: a phase 3 randomized placebo-controlled trial. Blood (2020) 135(24):2137-45. doi: 10.1182/blood.2020004856

4. Loke J, Malladi R, Moss P, Craddock C. The role of allogeneic stem cell transplantation in the management of acute myeloid leukaemia: a triumph of hope and experience. Br J Haematol (2020) 188(1):129-46. doi: 10.1111/ bjh.16355

5. Döhner H, Estey E, Grimwade D, Amadori S, Appelbaum FR, Büchner T, et al. Diagnosis and management of AML in adults: 2017 ELN 
recommendations from an international expert panel. Blood (2017) 129 (4):424-47. doi: 10.1182/blood-2016-08-733196

6. Schuurhuis GJ, Heuser M, Freeman S, Bene MC, Buccisano F, Cloos J, et al. Minimal/measurable residual disease in AML: a consensus document from the European LeukemiaNet MRD Working Party. Blood (2018) 131 (12):1275-91. doi: 10.1182/blood-2017-09-801498

7. Gooley TA, Chien JW, Pergam SA, Hingorani S, Sorror ML, Boeckh M, et al. Reduced Mortality after Allogeneic Hematopoietic-Cell Transplantation. N Engl J Med (2010) 363(22):2091-101. doi: 10.1056/NEJMoa1004383

8. Rambaldi A, Grassi A, Masciulli A, Boschini C, Mico MC, Busca A, et al. Busulfan plus cyclophosphamide versus busulfan plus fludarabine as a preparative regimen for allogeneic haemopoietic stem-cell transplantation in patients with acute myeloid leukaemia: an open-label, multicentre, randomised, phase 3 trial. Lancet Oncol (2015) 16(15):1525-36. doi: 10.1016/S1470-2045(15)00200-4

9. Scott BL, Pasquini MC, Logan BR, Wu J, Devine SM, Porter DL, et al. Myeloablative Versus Reduced-Intensity Hematopoietic Cell Transplantation for Acute Myeloid Leukemia and Myelodysplastic Syndromes. J Clin Oncol (2017) 35(11):1154-61. doi: 10.1200/JCO.2016.70.7091

10. Fasslrinner F, Schetelig J, Burchert A, Kramer M, Trenschel R, Hegenbart U, et al. Long-term efficacy of reduced-intensity versus myeloablative conditioning before allogeneic haemopoietic cell transplantation in patients with acute myeloid leukaemia in first complete remission: retrospective follow-up of an open-label, randomised phase 3 trial. Lancet Haematol (2018) 5(4):e161-e9. doi: 10.1016/S2352-3026(18)30022-X

11. Craddock C, Jackson A, Loke J, Siddique S, Hodgkinson A, Mason J, et al. Augmented Reduced-Intensity Regimen Does Not Improve Postallogeneic Transplant Outcomes in Acute Myeloid Leukemia. J Clin Oncol (2020) 0(0): JCO.20.02308. doi: 10.1200/JCO.20.02308

12. Gragert L, Eapen M, Williams E, Freeman J, Spellman S, Baitty R, et al. HLA Match Likelihoods for Hematopoietic Stem-Cell Grafts in the U.S. Registry (2014) 371(4):339-48. doi: 10.1056/NEJMsa1311707

13. Laughlin MJ, Barker J, Bambach B, Koc ON, Rizzieri DA, Wagner JE, et al. Hematopoietic engraftment and survival in adult recipients of umbilicalcord blood from unrelated donors. New Engl J Med (2001) 344(24):1815-22. doi: 10.1056/NEJM200106143442402

14. Passweg JR, Baldomero H, Basak GW, Chabannon C, Corbacioglu S, Duarte R, et al. The EBMT activity survey report 2017: a focus on allogeneic HCT for nonmalignant indications and on the use of non-HCT cell therapies. Bone Narrow Transplant (2019) 54(1):1575-85. doi: 10.1038/s41409-019-0465-9

15. Schmid C, Labopin M, Nagler A, Niederwieser D, Castagna L, Tabrizi R, et al. Treatment, risk factors, and outcome of adults with relapsed AML after reduced intensity conditioning for allogeneic stem cell transplantation. blood (2012) 119:(6):1599-606. doi: 10.1182/blood-2011-08-375840

16. Craddock C, Labopin M, Robin M, Finke J, Chevallier P, Yakoub-Agha I, et al. Clinical activity of azacitidine in patients who relapse after allogeneic stem cell transplantation for acute myeloid leukemia. Haematologica (2016) 101(7):879-83. doi: 10.3324/haematol.2015.140996

17. Craddock C, Slade D, Santo CD, Wheat R, Ferguson P, Hodgkinson A, et al. Combination Lenalidomide and Azacitidine: A Novel Salvage Therapy in Patients Who Relapse After Allogeneic Stem-Cell Transplantation for Acute Myeloid Leukemia. J Clin Oncol (2019) 37(7):580-8. doi: 10.1200/JCO.18.00889

18. Goodyear OC, Dennis M, Jilani NY, Loke J, Siddique S, Ryan G, et al. Azacitidine augments expansion of regulatory $\mathrm{T}$ cells after allogeneic stem cell transplantation in patients with acute myeloid leukemia (AML). Blood (2012) 119(14):3361-9. doi: 10.1182/blood-2011-09-377044

19. Craddock C, Jilani N, Siddique S, Yap C, Khan J, Nagra S, et al. Tolerability and Clinical Activity of Post-Transplantation Azacitidine in Patients Allografted for Acute Myeloid Leukemia Treated on the RICAZA Trial. Biol Blood Narrow Transplant (2016) 22(2):385-90. doi: 10.1016/j.bbmt.2015.09.004

20. Burchert A, Bug G, Fritz LV, Finke J, Stelljes M, Röllig C, et al. Sorafenib Maintenance After Allogeneic Hematopoietic Stem Cell Transplantation for Acute Myeloid Leukemia With FLT3-Internal Tandem Duplication Mutation (SORMAIN). J Clin Oncol (2020) 38(26):2993-3002. doi: 10.1200/JCO.19.03345

21. Platzbecker U, Middeke JM, Sockel K, Herbst R, Wolf D, Baldus CD, et al. Measurable residual disease-guided treatment with azacitidine to prevent haematological relapse in patients with myelodysplastic syndrome and acute myeloid leukaemia (RELAZA2): an open-label, multicentre, phase 2 trial. Lancet Oncol (2018) 19(12):1668-79. doi: 10.1016/S1470-2045(18)30580-1

22. Burnett AK, Goldstone A, Hills RK, Milligan D, Prentice A, Yin J, et al. Curability of Patients With Acute Myeloid Leukemia Who Did Not Undergo Transplantation in First Remission. J Clin Oncol (2013) 31(10):1293-301. doi: 10.1200/JCO.2011.40.5977

23. Michelis FV, Messner HA, Atenafu EG, Kim DD, Kuruvilla J, Lipton JH, et al. Benefit of Allogeneic Transplantation in Patients Age $\geq 60$ Years with Acute Myeloid Leukemia Is Limited to Those in First Complete Remission at Time of Transplant. Biol Blood Marrow Transplant (2014) 20(4):474-9. doi: 10.1016/j.bbmt.2013.12.560

24. Ding L, Ley TJ, Larson DE, Miller CA, Koboldt DC, Welch JS, et al. Clonal evolution in relapsed acute myeloid leukaemia revealed by whole-genome sequencing. Nature (2012) 481(7382):506-10. doi: 10.1038/nature10738

25. Bell CC, Fennell KA, Chan Y-C, Rambow F, Yeung MM, Vassiliadis D, et al. Targeting enhancer switching overcomes non-genetic drug resistance in acute myeloid leukaemia. Nat Commun (2019) 10(1):2723. doi: 10.1038/ s41467-019-10652-9

26. Sorror ML, Storb RF, Sandmaier BM, Maziarz RT, Pulsipher MA, Maris MB, et al. Comorbidity-Age Index: A Clinical Measure of Biologic Age Before Allogeneic Hematopoietic Cell Transplantation. J Clin Oncol (2014) 32 (29):3249-56. doi: 10.1200/JCO.2013.53.8157

27. Cornelissen JJ, Blaise D. Hematopoietic stem cell transplantation for patients with AML in first complete remission. Blood (2016) 127(1):62-70. doi: 10.1182/blood-2015-07-604546

28. Cornelissen JJ, van Putten WL, Verdonck LF, Theobald M, Jacky E, Daenen SM, et al. Results of a HOVON/SAKK donor versus no-donor analysis of myeloablative HLA-identical sibling stem cell transplantation in first remission acute myeloid leukemia in young and middle-aged adults: benefits for whom? Blood (2007) 109(9):3658-66. doi: 10.1182/blood-2006-06-025627

29. Cornelissen JJ, Breems D, Putten WLJV, Gratwohl AA, Passweg JR, Pabst T, et al. Comparative Analysis of the Value of Allogeneic Hematopoietic StemCell Transplantation in Acute Myeloid Leukemia With Monosomal Karyotype Versus Other Cytogenetic Risk Categories. J Clin Oncol (2012) 30(17):2140-6. doi: 10.1200/JCO.2011.39.6499

30. Burnett AK, Goldstone A, Hills RK, Milligan D, Prentice A, Yin J, et al. Curability of patients with acute myeloid leukemia who did not undergo transplantation in first remission. J Clin Oncol (2013) 31(10):1293-301. doi: 10.1200/JCO.2011.40.5977

31. Estey EH. Acute myeloid leukemia: 2019 update on risk-stratification and management. Am J Hematol (2018) 93(10):1267-91. doi: 10.1002/ajh.25214

32. Cornelissen J. The European LeukemiaNet AML Working Party consensus statement on allogeneic HSCT for patients with AML in remission: an integrated-risk adapted approach. Nat Rev Clin Oncol (2012) 9:579-90. doi: 10.1038/nrclinonc.2012.150

33. Grimwade D. Refinement of cytogenetic classification in acute myeloid leukemia: determination of prognostic significance of rare recurring chromosomal abnormalities among 5876 younger adult patients treated in the United Kingdom Medical Research Council trials. Blood (2010) 116:35465. doi: 10.1182/blood-2009-11-254441

34. Smith ML, Hills RK, Grimwade D. Independent prognostic variables in acute myeloid leukaemia. Blood Rev (2011) 25(1):39-51. doi: 10.1016/j.blre.2010.10.002

35. Papaemmanuil E, Gerstung M, Bullinger L, Gaidzik VI, Paschka P, Roberts ND, et al. Genomic Classification and Prognosis in Acute Myeloid Leukemia. New Engl J Med (2016) 374(23):2209-21. doi: 10.1056/NEJMoa1516192

36. Herold T, Rothenberg-Thurley M, Grunwald VV, Janke H, Goerlich D, Sauerland MC, et al. Validation and refinement of the revised 2017 European LeukemiaNet genetic risk stratification of acute myeloid leukemia. Leukemia (2020) 34:3161-72. doi: 10.1038/s41375-020-0806-0

37. Ravandi F, Jorgensen JL. Monitoring minimal residual disease in acute myeloid leukemia: ready for prime time? J Natl Compr Canc Netw (2012) 10 (8):1029-36. doi: 10.6004/jnccn.2012.0105

38. Dohner H, Estey E, Grimwade D, Amadori S, Appelbaum FR, Buchner T, et al. Diagnosis and management of AML in adults: 2017 ELN recommendations from an international expert panel. Blood (2017) 129 (4):424-47. doi: 10.1182/blood-2016-08-733196

39. Tallman MS, Rowlings PA, Milone G, Zhang MJ, Perez WS, Weisdorf D, et al. Effect of postremission chemotherapy before human leukocyte antigen-identical 
sibling transplantation for acute myelogenous leukemia in first complete remission. Blood (2000) 96(4):1254-8. doi: 10.1182/blood.V96.4.1254

40. Buckley SA, Wood BL, Othus M, Hourigan CS, Ustun C, Linden MA, et al. Minimal residual disease prior to allogeneic hematopoietic cell transplantation in acute myeloid leukemia: a meta-analysis. Haematologica (2017) 102(5):865-73. doi: 10.3324/haematol.2016.159343

41. Ghannam J, Dillon LW, Hourigan CS. Next-generation sequencing for measurable residual disease detection in acute myeloid leukaemia. $\mathrm{Br} J$ Haematol (2020) 188(1):77-85. doi: 10.1111/bjh.16362

42. Jongen-Lavrencic M, Grob T, Hanekamp D, Kavelaars FG, Hinai A, Zeilemaker A, et al. Molecular Minimal Residual Disease in Acute Myeloid Leukemia. New Engl J Med (2018) 378(13):1189-99. doi: 10.1056/ NEJMoa1716863

43. Hourigan CS, Dillon LW, Gui G, Logan BR, Fei M, Ghannam J, et al. Impact of Conditioning Intensity of Allogeneic Transplantation for Acute Myeloid Leukemia With Genomic Evidence of Residual Disease. J Clin Oncol (2020) 38(12):1273-83. doi: 10.1200/JCO.19.03011

44. Jourdan E, Boissel N, Chevret S, Delabesse E, Renneville A, Cornillet P, et al. Prospective evaluation of gene mutations and minimal residual disease in patients with core binding factor acute myeloid leukemia. Blood (2013) 121 (12):2213-23. doi: 10.1182/blood-2012-10-462879

45. Ivey A, Hills RK, Simpson MA, Jovanovic JV, Gilkes A, Grech A, et al. Assessment of Minimal Residual Disease in Standard-Risk AML. New Engl J Med (2016) 374(5):422-33. doi: 10.1056/NEJMoa1507471

46. Balsat M, Renneville A, Thomas X, Botton SD, Caillot D, Marceau A, et al. Postinduction Minimal Residual Disease Predicts Outcome and Benefit From Allogeneic Stem Cell Transplantation in Acute Myeloid Leukemia With NPM1 Mutation: A Study by the Acute Leukemia French Association Group. J Clin Oncol (2017) 35(2):185-93. doi: 10.1200/JCO.2016.67.1875

47. Rucker FG, Agrawal M, Corbacioglu A, Weber D, Kapp-Schwoerer S, Gaidzik VI, et al. Measurable residual disease monitoring in acute myeloid leukemia with $\mathrm{t}(8)$ (q22;q22.1): results from the AML Study Group. Blood (2019) 134(19):1608-18. doi: 10.1182/blood.2019001425

48. Krönke J, Schlenk RF, Jensen KO, Tschürtz F, Corbacioglu A, Gaidzik VI, et al. Monitoring of minimal residual disease in NPM1-mutated acute myeloid leukemia: a study from the German-Austrian acute myeloid leukemia study group. J Clin Oncol (2011) 29(19):2709-16. doi: 10.1200/JCO.2011.35.0371

49. Dillon R, Hills R, Freeman S, Potter N, Jovanovic J, Ivey A, et al. Molecular MRD status and outcome after transplantation in NPM1-mutated AML. Blood (2020) 135(9):680-8. doi: 10.1182/blood.2019002959

50. Tiong IS, Dillon R, Ivey A, Teh T-C, Nguyen P, Cummings N, et al. Venetoclax induces rapid elimination of NPM1 mutant measurable residual disease in combination with low-intensity chemotherapy in acute myeloid leukaemia. $\mathrm{Br}$ J Haematol (2021) 192(6):1026-30. doi: 10.1111/bjh.16722

51. Freeman SD, Hills RK, Virgo P, Khan N, Couzens S, Dillon R, et al. Measurable Residual Disease at Induction Redefines Partial Response in Acute Myeloid Leukemia and Stratifies Outcomes in Patients at Standard Risk Without NPM1 Mutations. J Clin Oncol (2018) 36(15):1486-97. doi: 10.1200/JCO.2017.76.3425

52. Sorror ML, Maris MB, Storb R, Baron F, Sandmaier BM, Maloney DG, et al. Hematopoietic cell transplantation (HCT)-specific comorbidity index: a new tool for risk assessment before allogeneic HCT. Blood (2005) 106(8):2912-9. doi: 10.1182/blood-2005-05-2004

53. Sorror ML, Giralt S, Sandmaier BM, De Lima M, Shahjahan M, Maloney DG, et al. Hematopoietic cell transplantation specific comorbidity index as an outcome predictor for patients with acute myeloid leukemia in first remission: combined FHCRC and MDACC experiences. Blood (2007) 110 (13):4606-13. doi: 10.1182/blood-2007-06-096966

54. Elsawy M, Storer BE, Milano F, Sandmaier BM, Delaney C, Salit RB, et al. Prognostic Performance of the Augmented Hematopoietic Cell Transplantation-Specific Comorbidity/Age Index in Recipients of Allogeneic Hematopoietic Stem Cell Transplantation from Alternative Graft Sources. Biol Blood Narrow Transplant (2019) 25(5):1045-52. doi: 10.1016/j.bbmt.2018.11.030

55. Gratwohl A, Stern M, Brand R, Apperley J, Baldomero H, de Witte T, et al. Risk score for outcome after allogeneic hematopoietic stem cell transplantation: a retrospective analysis. Cancer (2009) 115(20):4715-26. doi: $10.1002 /$ cncr.24531
56. Gratwohl A. The EBMT risk score. Bone Narrow Transplant (2012) 47 (6):749-56. doi: 10.1038/bmt.2011.110

57. Nikolousis E, Nagra S, Pearce R, Perry J, Kirkland K, Byrne J, et al. Impact of pre-transplant co-morbidities on outcome after alemtuzumab-based reduced intensity conditioning allo-SCT in elderly patients: a British Society of Blood and Marrow Transplantation study. Bone Narrow Transplant (2015) 50(1):82-6. doi: 10.1038/bmt.2014.215

58. Loke J, Labopin M, Craddock C, Niederwieser D, Cornelissen J, Afansayev B, et al. Impact of patient: donor HLA disparity on reduced-intensityconditioned allogeneic stem cell transplants from HLA mismatched unrelated donors for AML: from the ALWP of the EBMT. Bone Narrow Transplant (2020) 56:614-21. doi: 10.1038/s41409-020-01072-1

59. Grinfeld J, Nangalia J, Baxter EJ, Wedge DC, Angelopoulos N, Cantrill R, et al. Classification and Personalized Prognosis in Myeloproliferative Neoplasms. New Engl J Med (2018) 379(15):1416-30. doi: 10.1056/NEJMoa1716614

60. Shouval R, Labopin M, Bondi O, Mishan-Shamay H, Shimoni A, Ciceri F, et al. Prediction of Allogeneic Hematopoietic Stem-Cell Transplantation Mortality 100 Days After Transplantation Using a Machine Learning Algorithm: A European Group for Blood and Marrow Transplantation Acute Leukemia Working Party Retrospective Data Mining Study. J Clin Oncol (2015) 33(28):3144-51. doi: 10.1200/JCO.2014.59.1339

61. Marty FM, Ljungman P, Chemaly RF, Maertens J, Dadwal SS, Duarte RF, et al. Letermovir Prophylaxis for Cytomegalovirus in Hematopoietic-Cell Transplantation. N Engl J Med (2017) 377(25):2433-44. doi: 10.1056/ NEJMoa1706640

62. Dehn J, Spellman S, Hurley CK, Shaw BE, Barker JN, Burns LJ, et al. Selection of unrelated donors and cord blood units for hematopoietic cell transplantation: guidelines from the NMDP/CIBMTR. Blood (2019) 134 (12):924-34. doi: 10.1182/blood.2019001212

63. Verneris MR, Lee SJ, Ahn KW, Wang HL, Battiwalla M, Inamoto Y, et al. HLA Mismatch Is Associated with Worse Outcomes after Unrelated Donor Reduced-Intensity Conditioning Hematopoietic Cell Transplantation: An Analysis from the Center for International Blood and Marrow Transplant Research. Biol Blood Narrow Transplant (2015) 21(10):1783-9. doi: 10.1016/ j.bbmt.2015.05.028

64. Shaw BE, Mayor NP, Szydlo RM, Bultitude WP, Anthias C, Kirkland K, et al. Recipient/donor HLA and CMV matching in recipients of T-cell-depleted unrelated donor haematopoietic cell transplants. Bone Narrow Transplant (2017) 52(5):717-25. doi: 10.1038/bmt.2016.352

65. Schlenk RF, Döhner K, Mack S, Stoppel M, Király F, Götze K, et al. Prospective Evaluation of Allogeneic Hematopoietic Stem-Cell Transplantation From Matched Related and Matched Unrelated Donors in Younger Adults With High-Risk Acute Myeloid Leukemia: GermanAustrian Trial AMLHD98A. J Clin Oncol (2010) 28(30):4642-8. doi: 10.1200/JCO.2010.28.6856

66. Shaw BE, Logan BR, Spellman SR, Marsh SGE, Robinson J, Pidala J, et al. Development of an Unrelated Donor Selection Score Predictive of Survival after HCT: Donor Age Matters Most. Biol Blood Narrow Transplant (2018) 24(5):1049-56. doi: 10.1016/j.bbmt.2018.02.006

67. Kollman C, Spellman SR, Zhang MJ, Hassebroek A, Anasetti C, Antin JH, et al. The effect of donor characteristics on survival after unrelated donor transplantation for hematologic malignancy. Blood (2016) 127(2):260-7. doi: 10.1182/blood-2015-08-663823

68. Fleischhauer K, Shaw BE, Gooley T, Malkki M, Bardy P, Bignon JD, et al. Effect of T-cell-epitope matching at HLA-DPB1 in recipients of unrelateddonor haemopoietic-cell transplantation: a retrospective study. Lancet Oncol (2012) 13(4):366-74. doi: 10.1016/S1470-2045(12)70004-9

69. Frick M, Chan W, Arends CM, Hablesreiter R, Halik A, Heuser M, et al. Role of Donor Clonal Hematopoiesis in Allogeneic Hematopoietic Stem-Cell Transplantation. J Clin Oncol (2019) 37(5):375-85. doi: 10.1200/ JCO.2018.79.2184

70. Brunstein CG, Fuchs EJ, Carter SL, Karanes C, Costa LJ, Wu J, et al. Alternative donor transplantation after reduced intensity conditioning: results of parallel phase 2 trials using partially HLA-mismatched related bone marrow or unrelated double umbilical cord blood grafts. Blood (2011) 118(2):282-8. doi: 10.1182/blood-2011-03-344853

71. Ruggeri A, Labopin M, Savani B, Paviglianiti A, Blaise D, Volt F, et al. Hematopoietic stem cell transplantation with unrelated cord blood or 
haploidentical donor grafts in adult patients with secondary acute myeloid leukemia, a comparative study from Eurocord and the ALWP EBMT. Bone Narrow Transplant (2019) 54:1987-94. doi: 10.1038/s41409-019-0582-5

72. Versluis J, Labopin M, Ruggeri A, Socie G, Wu D, Volin L, et al. Alternative donors for allogeneic hematopoietic stem cell transplantation in poor-risk AML in CR1. Blood Adv. (2017) 1(7):477-85. doi: 10.1182/ bloodadvances.2016002386

73. Fuchs EJ, O’Donnell PV, Eapen M, Logan BR, Antin JH, Dawson P, et al. Double unrelated umbilical cord blood versus HLA-haploidentical bone marrow transplantation (BMT CTN 1101). Blood (2020) 137(3):420-8. doi: 10.1182/blood.2020007535

74. Mehta RS, Holtan SG, Wang T, Hemmer MT, Spellman SR, Arora M, et al. Composite GRFS and CRFS Outcomes After Adult Alternative Donor HCT. J Clin Oncol (2020) 38(18):2062-76. doi: 10.1200/JCO.19.00396

75. Ferguson P, Hills RK, Grech A, Betteridge S, Kjeldsen L, Dennis M, et al. An operational definition of primary refractory acute myeloid leukaemia allowing early identification of patients who may benefit from allogeneic stem cell transplantation. Haematologica (2016) 101(11):1351-8. doi: 10.3324/haematol.2016.148825

76. Duval M, Klein JP, He W, Cahn JY, Cairo M, Camitta BM, et al. Hematopoietic stem-cell transplantation for acute leukemia in relapse or primary induction failure. J Clin Oncol (2010) 28(23):3730-8. doi: 10.1200/JCO.2010.28.8852

77. Gale RP, Horowitz MM, Rees JK, Gray RG, Oken MM, Estey EH, et al. Chemotherapy versus transplants for acute myelogenous leukemia in second remission. Leukemia (1996) 10(1):13-9.

78. Middeke JM, Beelen D, Stadler M, Göhring G, Schlegelberger B, Baurmann $\mathrm{H}$, et al. Outcome of high-risk acute myeloid leukemia after allogeneic hematopoietic cell transplantation: negative impact of abnl(17p) and $-5 / 5 q-$. Blood (2012) 120(12):2521-8. doi: 10.1182/blood-2012-03-417972

79. Rautenberg C, Germing U, Haas R, Kobbe G, Schroeder T. Relapse of Acute Myeloid Leukemia after Allogeneic Stem Cell Transplantation: Prevention, Detection, and Treatment. Int J Mol Sci (2019) 20(1):228. doi: 10.3390/ ijms20010228

80. Brunet S, Labopin M, Esteve J, Cornelissen J, Socié G, Iori AP, et al. Impact of FLT3 internal tandem duplication on the outcome of related and unrelated hematopoietic transplantation for adult acute myeloid leukemia in first remission: a retrospective analysis. J Clin Oncol (2012) 30(7):735-41. doi: 10.1200/JCO.2011.36.9868

81. Ciurea SO, Kongtim P, Varma A, Rondon G, Chen J, Srour S, et al. Is there an optimal conditioning for older patients with AML receiving allogeneic hematopoietic cell transplantation? Blood (2020) 135(6):449-52. doi: 10.1182/blood.2019003662

82. Michallet M, Bilger K, Garban F, Attal M, Huyn A, Blaise D, et al. Allogeneic Hematopoietic Stem-Cell Transplantation After Nonmyeloablative Preparative Regimens: Impact of Pretransplantation and Posttransplantation Factors on Outcome. J Clin Oncol (2001) 19(14):3340-9. doi: 10.1200/JCO.2001.19.14.3340

83. Charles C, Sandeep N, Andrew P, Cassandra B, Laura B, Emmanouil N, et al. Factors predicting long-term survival after T-cell depleted reduced intensity allogeneic stem cell transplantation for acute myeloid leukemia. Haematologica (2010) 95(6):989-95. doi: 10.3324/haematol.2009.013920

84. Araki D, Wood BL, Othus M, Radich JP, Halpern AB, Zhou Y, et al. Allogeneic Hematopoietic Cell Transplantation for Acute Myeloid Leukemia: Time to Move Toward a Minimal Residual Disease-Based Definition of Complete Remission? J Clin Oncol (2016) 34(4):329-36. doi: 10.1200/JCO.2015.63.3826

85. Ossenkoppele GJ, Janssen JJWM, van de Loosdrecht AA. Risk factors for relapse after allogeneic transplantation in acute myeloid leukemia. Haematologica (2016) 101(1):20-5. doi: 10.3324/haematol.2015.139105

86. Kim T, Moon JH, Ahn J-S, Kim Y-K, Lee S-S, Ahn S-Y, et al. Next-generation sequencing based post-transplant monitoring of acute myeloid leukemia. Blood (2018) 132(15):1604-13. doi: 10.1182/blood-2018-04-848028

87. Shah MV, Jorgensen JL, Saliba RM, Wang SA, Alousi AM, Andersson BS, et al. Early Post-Transplant Minimal Residual Disease Assessment Improves Risk Stratification in Acute Myeloid Leukemia. Biol Blood Marrow Transplant (2018) 24(7):1514-20. doi: 10.1016/j.bbmt.2018.02.003

88. Warlick ED, Paulson K, Brazauskas R, Zhong X, Miller AM, Camitta BM, et al. Effect of postremission therapy before reduced-intensity conditioning allogeneic transplantation for acute myeloid leukemia in first complete remission. Biol Blood Narrow Transplant (2014) 20(2):202-8. doi: 10.1016/ j.bbmt.2013.10.023

89. Loke J, Khan JN, Wilson JS, Craddock C, Wheatley K. Mylotarg has potent anti-leukaemic effect: a systematic review and meta-analysis of anti-CD33 antibody treatment in acute myeloid leukaemia. Ann Hematol (2015) 94 (3):361-73. doi: 10.1007/s00277-014-2218-6

90. Lancet JE, Uy GL, Cortes JE, Newell LF, Lin TL, Ritchie EK, et al. CPX-351 (cytarabine and daunorubicin) Liposome for Injection Versus Conventional Cytarabine Plus Daunorubicin in Older Patients With Newly Diagnosed Secondary Acute Myeloid Leukemia. J Clin Oncol (2018) 36(26):2684-92. doi: 10.1200/JCO.2017.77.6112

91. Cortes JE, Khaled S, Martinelli G, Perl AE, Ganguly S, Russell N, et al. Quizartinib versus salvage chemotherapy in relapsed or refractory FLT3ITD acute myeloid leukaemia (QuANTUM-R): a multicentre, randomised, controlled, open-label, phase 3 trial. Lancet Oncol (2019) 20(7):984-97. doi: 10.1016/S1470-2045(19)30150-0

92. Perl AE, Martinelli G, Cortes JE, Neubauer A, Berman E, Paolini S, et al. Gilteritinib or Chemotherapy for Relapsed or Refractory FLT3-Mutated AML. New Engl J Med (2019) 381(18):1728-40. doi: 10.1056/NEJMoa1902688

93. Krauss AC, Gao X, Li L, Manning ML, Patel P, Fu W, et al. FDA Approval Summary: (Daunorubicin and Cytarabine) Liposome for Injection for the Treatment of Adults with High-Risk Acute Myeloid Leukemia. Clin Cancer Res (2019) 25(9):2685-90. doi: 10.1158/1078-0432.CCR-18-2990

94. DiNardo CD, Jonas BA, Pullarkat V, Thirman MJ, Garcia JS, Wei AH, et al. Azacitidine and Venetoclax in Previously Untreated Acute Myeloid Leukemia. New Engl J Med (2020) 383(7):617-29. doi: 10.1056/NEJMoa2012971

95. Voso MT, Leone G, Piciocchi A, Fianchi L, Santarone S, Candoni A, et al. Feasibility of allogeneic stem-cell transplantation after azacitidine bridge in higher-risk myelodysplastic syndromes and low blast count acute myeloid leukemia: results of the BMT-AZA prospective study. Ann Oncol (2017) 28 (7):1547-53. doi: 10.1093/annonc/mdx154

96. Clift RA, Buckner CD, Appelbaum FR, Bearman SI, Petersen FB, Fisher LD, et al. Allogeneic marrow transplantation in patients with acute myeloid leukemia in first remission: a randomized trial of two irradiation regimens. Blood (1990) 76(9):1867-71. doi: 10.1182/blood.V76.9.1867.1867

97. Thomas ED, Lochte HLJr, Lu WC, Ferrebee JW. Intravenous infusion of bone marrow in patients receiving radiation and chemotherapy. New Engl J Med (1957) 257(11):491-6. doi: 10.1056/NEJM195709122571102

98. Bredeson C, LeRademacher J, Kato K, Dipersio JF, Agura E, Devine SM, et al. Prospective cohort study comparing intravenous busulfan to total body irradiation in hematopoietic cell transplantation. Blood (2013) 122 (24):3871-8. doi: 10.1182/blood-2013-08-519009

99. Bacigalupo A, Ballen K, Rizzo D, Giralt S, Lazarus H, Ho V, et al. Defining the intensity of conditioning regimens: working definitions. Biol Blood Narrow Transplant (2009) 15(12):1628-33. doi: 10.1016/j.bbmt.2009.07.004

100. Ringdén O, Boumendil A, Labopin M, Canaani J, Beelen D, Ehninger G, et al. Outcome of Allogeneic Hematopoietic Stem Cell Transplantation in Patients Age >69 Years with Acute Myelogenous Leukemia: On Behalf of the Acute Leukemia Working Party of the European Society for Blood and Marrow Transplantation. Biol Blood Marrow Transplant (2019) 25(10):1975-83. doi: 10.1016/j.bbmt.2019.05.037

101. Muffly L, Pasquini MC, Martens M, Brazauskas R, Zhu X, Adekola K, et al. Increasing use of allogeneic hematopoietic cell transplantation in patients aged 70 years and older in the United States. Blood (2017) 130(9):1156-64. doi: 10.1182/blood-2017-03-772368

102. Blaise D, Tabrizi R, Boher JM, Le Corroller-Soriano AG, Bay JO, Fegueux N, et al. Randomized study of 2 reduced-intensity conditioning strategies for human leukocyte antigen-matched, related allogeneic peripheral blood stem cell transplantation: prospective clinical and socioeconomic evaluation. Cancer (2013) 119(3):602-11. doi: 10.1002/cncr.27786

103. Beelen DW, Trenschel R, Stelljes M, Groth C, Masszi T, Reményi P, et al. Treosulfan or busulfan plus fludarabine as conditioning treatment before allogeneic haemopoietic stem cell transplantation for older patients with acute myeloid leukaemia or myelodysplastic syndrome (MC-FludT.14/L): a randomised, non-inferiority, phase 3 trial. Lancet Haematol (2020) 7(1):e2839. doi: 10.1016/S2352-3026(19)30157-7

104. Kroger N, Iacobelli S, Franke GN, Platzbecker U, Uddin R, Hubel K, et al. Dose-Reduced Versus Standard Conditioning Followed by Allogeneic Stem- 
Cell Transplantation for Patients With Myelodysplastic Syndrome: A Prospective Randomized Phase III Study of the EBMT (RICMAC Trial). J Clin Oncol (2017) 35(19):2157-64. doi: 10.1200/JCO.2016.70.7349

105. Bornhäuser M, Kienast J, Trenschel R, Burchert A, Hegenbart U, Stadler M, et al. Reduced-intensity conditioning versus standard conditioning before allogeneic haemopoietic cell transplantation in patients with acute myeloid leukaemia in first complete remission: a prospective, open-label randomised phase 3 trial. Lancet Oncol (2012) 13(10):1035-44. doi: 10.1016/S1470-2045(12)70349-2

106. Scott BL. Long-Term Follow up of BMT CTN 0901, a Randomized Phase III Trial Comparing Myeloablative (MAC) to Reduced Intensity Conditioning (RIC) Prior to Hematopoietic Cell Transplantation (HCT) for Acute Myeloid Leukemia (AML) or Myelodysplasia (MDS) (MAvRIC Trial). Biol Blood Marrow Transplant (2020) 26(3, Supplement):S11. doi: 10.1016/j.bbmt.2019.12.075

107. Sanz J, Sanz MA, Saavedra S, Lorenzo I, Montesinos P, Senent L, et al. Cord blood transplantation from unrelated donors in adults with high-risk acute myeloid leukemia. Biol Blood Narrow Transplant (2010) 16(1):86-94. doi: 10.1016/j.bbmt.2009.09.001

108. Sora F, Sica S, Di Grazia C, Chiusolo P, Laurenti L, Mordini N, et al. Busulfan Fludarabine (BU-FLU) Compared to Thiotepa Busulfan Fludarabine (TBF) for Allogeneic Transplants in Acute Myeloid Leukemia (AML) or Refractory Anemia with Excess Blasts (RAEB) in Remission. Blood (2017) 130 (Supplement 1):909-. doi: 10.1182/blood.V130.Suppl_1.909.909

109. Saraceni F, Labopin M, Hamladji R-M, Mufti G, Socié G, Shimoni A, et al. Thiotepa-busulfan-fludarabine compared to busulfan-fludarabine for sibling and unrelated donor transplant in acute myeloid leukemia in first remission. Oncotarget (2017) 9(3):3379-93. doi: 10.18632/oncotarget.23273

110. El-Cheikh J, Labopin M, Al-Chami F, Bazarbachi A, Angelucci E, Santarone $\mathrm{S}$, et al. Effect of the Thiotepa Dose in the TBF Conditioning Regimen in Patients Undergoing Allogeneic Stem Cell Transplantation for Acute Myeloid Leukemia in Complete Remission: A Report From the EBMT Acute Leukemia Working Party. Clin Lymphoma Myeloma Leuk (2020) 20 (5):296-304. doi: 10.1016/j.clml.2020.01.007

111. Popat UR, Mehta RS, Bassett R, Chen J, Valdez BC, Kawedia J, et al. Fludarabine with a higher versus lower dose of myeloablative timedsequential busulfan in older patients and patients with comorbidities: an open-label, non-stratified, randomised phase 2 trial. Lancet Haematol (2018) 5(11):e532-e42. doi: 10.1016/S2352-3026(18)30156-X

112. Pagel JM, Gooley TA, Rajendran J, Fisher DR, Wilson WA, Sandmaier BM, et al. Allogeneic hematopoietic cell transplantation after conditioning with 131I-anti-CD45 antibody plus fludarabine and low-dose total body irradiation for elderly patients with advanced acute myeloid leukemia or high-risk myelodysplastic syndrome. Blood (2009) 114(27):5444-53. doi: 10.1182/blood-2009-03-213298

113. Holtan SG, DeFor TE, Lazaryan A, Bejanyan N, Arora M, Brunstein CG, et al. Composite end point of graft-versus-host disease-free, relapse-free survival after allogeneic hematopoietic cell transplantation. Blood (2015) 125 (8):1333-8. doi: 10.1182/blood-2014-10-609032

114. Weiden PL, Flournoy N, Thomas ED, Prentice R, Fefer A, Buckner CD, et al. Antileukemic effect of graft-versus-host disease in human recipients of allogeneic-marrow grafts. New Engl J Med (1979) 300(19):1068-73. doi: 10.1056/NEJM197905103001902

115. Craddock C, Nagra S, Peniket A, Brookes C, Buckley L, Nikolousis E, et al. Factors predicting long-term survival after T-cell depleted reduced intensity allogeneic stem cell transplantation for acute myeloid leukemia. Haematologica (2010) 95(6):989-95. doi: 10.3324/haematol.2009.013920

116. Bacigalupo A, Vitale V, Corvo R, Barra S, Lamparelli T, Gualandi F, et al. The combined effect of total body irradiation (TBI) and cyclosporin A (CyA) on the risk of relapse in patients with acute myeloid leukaemia undergoing allogeneic bone marrow transplantation. Br J Haematol (2000) 108(1):99104. doi: 10.1046/j.1365-2141.2000.01809.x

117. Pasquini MC, Devine S, Mendizabal A, Baden LR, Wingard JR, Lazarus HM, et al. Comparative outcomes of donor graft $\mathrm{CD} 34+$ selection and immune suppressive therapy as graft-versus-host disease prophylaxis for patients with acute myeloid leukemia in complete remission undergoing HLA-matched sibling allogeneic hematopoietic cell transplantation. J Clin Oncol (2012) 30 (26):3194-201. doi: 10.1200/JCO.2012.41.7071

118. Bacigalupo A, Lamparelli T, Bruzzi P, Guidi S, Alessandrino PE, di Bartolomeo P, et al. Antithymocyte globulin for graft-versus-host disease prophylaxis in transplants from unrelated donors: 2 randomized studies from Gruppo Italiano Trapianti Midollo Osseo (GITMO). Blood (2001) 98 (10):2942-7. doi: 10.1182/blood.V98.10.2942

119. Chakraverty R, Orti G, Roughton M, Shen J, Fielding A, Kottaridis P, et al. Impact of in vivo alemtuzumab dose before reduced intensity conditioning and HLA-identical sibling stem cell transplantation: pharmacokinetics, GVHD, and immune reconstitution. Blood (2010) 116(16):3080-8. doi: 10.1182/blood-2010-05-286856

120. Soiffer RJ, LeRademacher J, Ho V, Kan F, Artz A, Champlin RE, et al. Impact of immune modulation with anti-T-cell antibodies on the outcome of reduced-intensity allogeneic hematopoietic stem cell transplantation for hematologic malignancies. Blood (2011) 117(25):6963-70. doi: 10.1182/ blood-2011-01-332007

121. Perez-Simon JA, Kottaridis PD, Martino R, Craddock C, Caballero D, Chopra R, et al. Nonmyeloablative transplantation with or without alemtuzumab: comparison between 2 prospective studies in patients with lymphoproliferative disorders. Blood (2002) 100(9):3121-7. doi: 10.1182/ blood-2002-03-0701

122. Luznik L, O'Donnell PV, Symons HJ, Chen AR, Leffell MS, Zahurak M, et al. HLA-haploidentical bone marrow transplantation for hematologic malignancies using nonmyeloablative conditioning and high-dose, posttransplantation cyclophosphamide. Biol Blood Narrow Transplant (2008) 14(6):641-50. doi: 10.1016/j.bbmt.2008.03.005

123. Battipaglia G, Labopin M, Kroger N, Vitek A, Afanasyev B, Hilgendorf I, et al. Posttransplant cyclophosphamide vs antithymocyte globulin in HLAmismatched unrelated donor transplantation. Blood (2019) 134(11):892-9. doi: 10.1182/blood.2019000487

124. Bolaños-Meade J, Reshef R, Fraser R, Fei M, Abhyankar S, Al-Kadhimi Z, et al. Three prophylaxis regimens (tacrolimus, mycophenolate mofetil, and cyclophosphamide; tacrolimus, methotrexate, and bortezomib; or tacrolimus, methotrexate, and maraviroc) versus tacrolimus and methotrexate for prevention of graft-versus-host disease with haemopoietic cell transplantation with reduced-intensity conditioning: a randomised phase 2 trial with a non-randomised contemporaneous control group (BMT CTN 1203). Lancet Haematol (2019) 6(3):e132-e43. doi: 10.1016/ S2352-3026(18)30221-7

125. Craddock C, Labopin M, Pillai S, Finke J, Bunjes D, Greinix H, et al. Factors predicting outcome after unrelated donor stem cell transplantation in primary refractory acute myeloid leukaemia. Leukemia (2011) 25(5):80813. doi: $10.1038 /$ leu.2011.13

126. Zhou Y, Othus M, Araki D, Wood BL, Radich JP, Halpern AB, et al. Pre- and post-transplant quantification of measurable ('minimal') residual disease via multiparameter flow cytometry in adult acute myeloid leukemia. Leukemia (2016) 30(7):1456-64. doi: 10.1038/leu.2016.46

127. Duncavage EJ, Jacoby MA, Chang GS, Miller CA, Edwin N, Shao J, et al. Mutation Clearance after Transplantation for Myelodysplastic Syndrome. New Engl J Med (2018) 379(11):1028-41. doi: 10.1056/NEJMoa1804714

128. Wang $\mathrm{Y}, \mathrm{Wu} \mathrm{DP}$, Liu QF, Qin YZ, Wang JB, Xu LP, et al. In adults with $\mathrm{t}$ (8;21)AML, posttransplant RUNX1/RUNX1T1-based MRD monitoring, rather than c-KIT mutations, allows further risk stratification. Blood (2014) 124(12):1880-6. doi: 10.1182/blood-2014-03-563403

129. Shayegi N, Kramer M, Bornhäuser M, Schaich M, Schetelig J, Platzbecker U, et al. The level of residual disease based on mutant NPM1 is an independent prognostic factor for relapse and survival in AML. Blood (2013) 122(1):8392. doi: 10.1182/blood-2012-10-461749

130. Yan C-H, Liu D-H, Liu K-Y, Xu L-P, Liu Y-R, Chen H, et al. Risk stratification-directed donor lymphocyte infusion could reduce relapse of standard-risk acute leukemia patients after allogeneic hematopoietic stem cell transplantation. Blood (2012) 119(14):3256-62. doi: 10.1182/blood2011-09-380386

131. Schmid C, Labopin M, Nagler A, Bornhauser M, Finke J, Fassas A, et al. Donor lymphocyte infusion in the treatment of first hematological relapse after allogeneic stem-cell transplantation in adults with acute myeloid leukemia: a retrospective risk factors analysis and comparison with other strategies by the EBMT Acute Leukemia Working Party. J Clin Oncol (2007) 25(31):4938-45. doi: 10.1200/JCO.2007.11.6053

132. Hofmann S, Götz M, Schneider V, Guillaume P, Bunjes D, Döhner H, et al. Donor Lymphocyte Infusion Induces Polyspecific CD8+ T-Cell Responses With 
Concurrent Molecular Remission in Acute Myeloid Leukemia With NPM1 Mutation. J Clin Oncol (2013) 31(3):e44-e7. doi: 10.1200/JCO.2011.41.1116

133. Wermke M, Thiede C, Kiani A, Ehninger G, Bornhäuser M, Platzbecker U. Successful treatment of molecular relapse in NPM1-positive AML using 5azacytidine. Leukemia (2010) 24(1):236-7. doi: 10.1038/leu.2009.204

134. Lee HC, Saliba RM, Rondon G, Chen J, Charafeddine Y, Medeiros LJ, et al. Mixed T Lymphocyte Chimerism after Allogeneic Hematopoietic Transplantation Is Predictive for Relapse of Acute Myeloid Leukemia and Myelodysplastic Syndromes. Biol Blood Marrow Transplant (2015) 21 (11):1948-54. doi: 10.1016/j.bbmt.2015.07.005

135. Bader P, Beck J, Frey A, Schlegel PG, Hebarth H, Handgretinger R, et al. Serial and quantitative analysis of mixed hematopoietic chimerism by PCR in patients with acute leukemias allows the prediction of relapse after allogeneic BMT. Bone Narrow Transplant (1998) 21(5):487-95. doi: 10.1038/ sj.bmt.1701119

136. Marsh RA, Lane A, Mehta PA, Neumeier L, Jodele S, Davies SM, et al. Alemtuzumab levels impact acute GVHD, mixed chimerism, and lymphocyte recovery following alemtuzumab, fludarabine, and melphalan RIC HCT. Blood (2016) 127(4):503-12. doi: 10.1182/blood-2015-07-659672

137. Sellmann L, Rabe K, Bünting I, Dammann E, Göhring G, Ganser A, et al. Diagnostic value of highly-sensitive chimerism analysis after allogeneic stem cell transplantation. Bone Narrow Transplant (2018) 53(11):1457-65. doi: 10.1038/s41409-018-0176-7

138. Mathew NR, Baumgartner F, Braun L, O'Sullivan D, Thomas S, Waterhouse $\mathrm{M}$, et al. Sorafenib promotes graft-versus-leukemia activity in mice and humans through IL-15 production in FLT3-ITD-mutant leukemia cells. Nat Med (2018) 24(3):282-91. doi: 10.1038/nm.4484

139. Jan M, Leventhal MJ, Morgan EA, Wengrod JC, Nag A, Drinan SD, et al. Recurrent genetic HLA loss in AML relapsed after matched unrelated allogeneic hematopoietic cell transplantation. Blood Adv (2019) 3 (14):2199-204. doi: 10.1182/bloodadvances.2019000445

140. Quek L, Ferguson P, Metzner M, Ahmed I, Kennedy A, Garnett C, et al. Mutational analysis of disease relapse in patients allografted for acute myeloid leukemia. Blood Adv (2016) 1(3):193-204. doi: 10.1182/ bloodadvances.2016000760

141. Sockel K, Bornhaeuser M, Mischak-Weissinger E, Trenschel R, Wermke M, Unzicker C, et al. Lenalidomide maintenance after allogeneic HSCT seems to trigger acute graft-versus-host disease in patients with high-risk myelodysplastic syndromes or acute myeloid leukemia and del(5q): results of the LENAMAINT trial. Haematologica (2012) 97(9):e34-e5. doi: 10.3324/ haematol.2012.067629

142. Oran B, de Lima M, Garcia-Manero G, Thall PF, Lin R, Popat U, et al. A phase 3 randomized study of 5 -azacitidine maintenance vs observation after transplant in high-risk AML and MDS patients. Blood Adv (2020) 4 (21):5580-8. doi: 10.1182/bloodadvances.2020002544

143. Wei AH, Döhner H, Pocock C, Montesinos P, Afanasyev B, Dombret H, et al. The QUAZAR AML-001 Maintenance Trial: Results of a Phase III International, Randomized, Double-Blind, Placebo-Controlled Study of CC-486 (Oral Formulation of Azacitidine) in Patients with Acute Myeloid Leukemia (AML) in First Remission. Blood (2019) 134(Supplement_2):LBA3-LBA-. doi: 10.1182/blood-2019-132405

144. de Lima M, Oran B, Champlin RE, Papadopoulos EB, Giralt SA, Scott BL, et al. CC-486 Maintenance after Stem Cell Transplantation in Patients with Acute Myeloid Leukemia or Myelodysplastic Syndromes. Biol Blood Narrow Transplant (2018) 24(10):2017-24. doi: 10.1016/j.bbmt.2018.06.016

145. DiNardo CD, Wei AH. How I treat acute myeloid leukemia in the era of new drugs. Blood (2020) 135(2):85-96. doi: 10.1182/blood.2019001239

146. Queiroz KC, Ruela-de-Sousa RR, Fuhler GM, Aberson HL, Ferreira CV, Peppelenbosch MP, et al. Hedgehog signaling maintains chemoresistance in myeloid leukemic cells. Oncogene (2010) 29(48):6314-22. doi: 10.1038/ onc.2010.375

147. Cortes JE, Heidel FH, Hellmann A, Fiedler W, Smith BD, Robak T, et al. Randomized comparison of low dose cytarabine with or without glasdegib in patients with newly diagnosed acute myeloid leukemia or high-risk myelodysplastic syndrome. Leukemia (2019) 33(2):379-89. doi: 10.1038/ s41375-018-0312-9
148. Stein EM, DiNardo CD, Pollyea DA, Fathi AT, Roboz GJ, Altman JK, et al. Enasidenib in mutant-IDH2 relapsed or refractory acute myeloid leukemia. Blood (2017) 130(6):722-31. doi: 10.1182/blood-2017-04-779405

149. DiNardo CD, Stein EM, de Botton S, Roboz GJ, Altman JK, Mims AS, et al. Durable Remissions with Ivosidenib in IDH1-Mutated Relapsed or Refractory AML. New Engl J Med (2018) 378(25):2386-98. doi: 10.1056/ NEJMoa1716984

150. Smith CC. The growing landscape of FLT3 inhibition in AML. Hematology (2019) 2019(1):539-47. doi: 10.1182/hematology.2019000058

151. Kottaridis PD, Gale RE, Frew ME, Harrison G, Langabeer SE, Belton AA, et al. The presence of a FLT3 internal tandem duplication in patients with acute myeloid leukemia (AML) adds important prognostic information to cytogenetic risk group and response to the first cycle of chemotherapy: analysis of 854 patients from the United Kingdom Medical Research Council AML 10 and 12 trials. Blood (2001) 98(6):1752-9. doi: 10.1182/blood.V98.6.1752

152. Röllig C, Serve H, Hüttmann A, Noppeney R, Müller-Tidow C, Krug U, et al. Addition of sorafenib versus placebo to standard therapy in patients aged 60 years or younger with newly diagnosed acute myeloid leukaemia (SORAML): a multicentre, phase 2, randomised controlled trial. Lancet Oncol (2015) 16 (16):1691-9. doi: 10.1016/S1470-2045(15)00362-9

153. Schlenk RF, Weber D, Fiedler W, Salih HR, Wulf G, Salwender H, et al. Midostaurin added to chemotherapy and continued single-agent maintenance therapy in acute myeloid leukemia with FLT3-ITD. Blood (2019) 133(8):840-51. doi: 10.1182/blood-2018-08-869453

154. Maziarz RTT, Patnaik MM, Scott BL, Mohan SR, Deol A, Rowley SD, et al. Radius: A Phase 2 Randomized Trial Investigating Standard of Care \pm Midostaurin after Allogeneic Stem Cell Transplant in FLT3-ITD-Mutated AML. Blood (2018) 132(Supplement 1):662-. doi: 10.1182/blood-2018-99-113582

155. Xuan L, Wang Y, Huang F, Fan Z, Xu Y, Sun J, et al. Sorafenib maintenance in patients with FLT3-ITD acute myeloid leukaemia undergoing allogeneic haematopoietic stem-cell transplantation: an open-label, multicentre, randomised phase 3 trial. Lancet Oncol (2020) 21(9):1201-12. doi: 10.1016/S1470-2045(20)30455-1

156. Levis MJ, Chen Y-B, Hamadani M, Horowitz MM, Jones RJ, Blood, et al. FLT3 Inhibitor Maintenance After Allogeneic Transplantation: Is a PlaceboControlled, Randomized Trial Ethical? J Clin Oncol (2019) 37(19):1604-7. doi: 10.1200/JCO.19.00321

157. Daver N, Garcia-Manero G, Basu S, Boddu PC, Alfayez M, Cortes JE, et al. Efficacy, Safety, and Biomarkers of Response to Azacitidine and Nivolumab in Relapsed/Refractory Acute Myeloid Leukemia: A Non-randomized, Open-label, Phase 2 Study. Cancer Discovery (2018) 9(3):370-383. doi: 10.1158/2159-8290.CD-18-0774

158. Björklund AT, Carlsten M, Sohlberg E, Liu LL, Clancy T, Karimi M, et al. Complete Remission with Reduction of High-Risk Clones following Haploidentical NK-Cell Therapy against MDS and AML. Clin Cancer Res (2018) 24(8):1834-44. doi: 10.1158/1078-0432.CCR-17-3196

159. Cooley S, He F, Bachanova V, Vercellotti GM, DeFor TE, Curtsinger JM, et al. First-in-human trial of rhIL-15 and haploidentical natural killer cell therapy for advanced acute myeloid leukemia. Blood Adv (2019) 3(13):197080. doi: 10.1182/bloodadvances.2018028332

Conflict of Interest: CC has received honoraria from Celgene, Daichi-Sankyo, Novartis, and Pfizer as well as research funding from Celgene. JL has received travel funding from Novartis and Daichi-Sankyo, and honoraria from Pfizer, Janssen, and Amgen.

The remaining author declares that the research was conducted in the absence of any commercial or financial relationships that could be construed as a potential conflict of interest.

Copyright ( 2021 Loke, Vyas and Craddock. This is an open-access article distributed under the terms of the Creative Commons Attribution License (CC BY). The use, distribution or reproduction in other forums is permitted, provided the original author(s) and the copyright owner(s) are credited and that the original publication in this journal is cited, in accordance with accepted academic practice. No use, distribution or reproduction is permitted which does not comply with these terms. 